Prepared in cooperation with National Oceanic and Atmospheric Administration, National Marine Fisheries Service

\title{
Using the STARS Model to Evaluate the Effects of the Proposed Action for the Reinitiation of Consultation on the Coordinated Long-Term Operation of the Central Valley and State Water Project
}

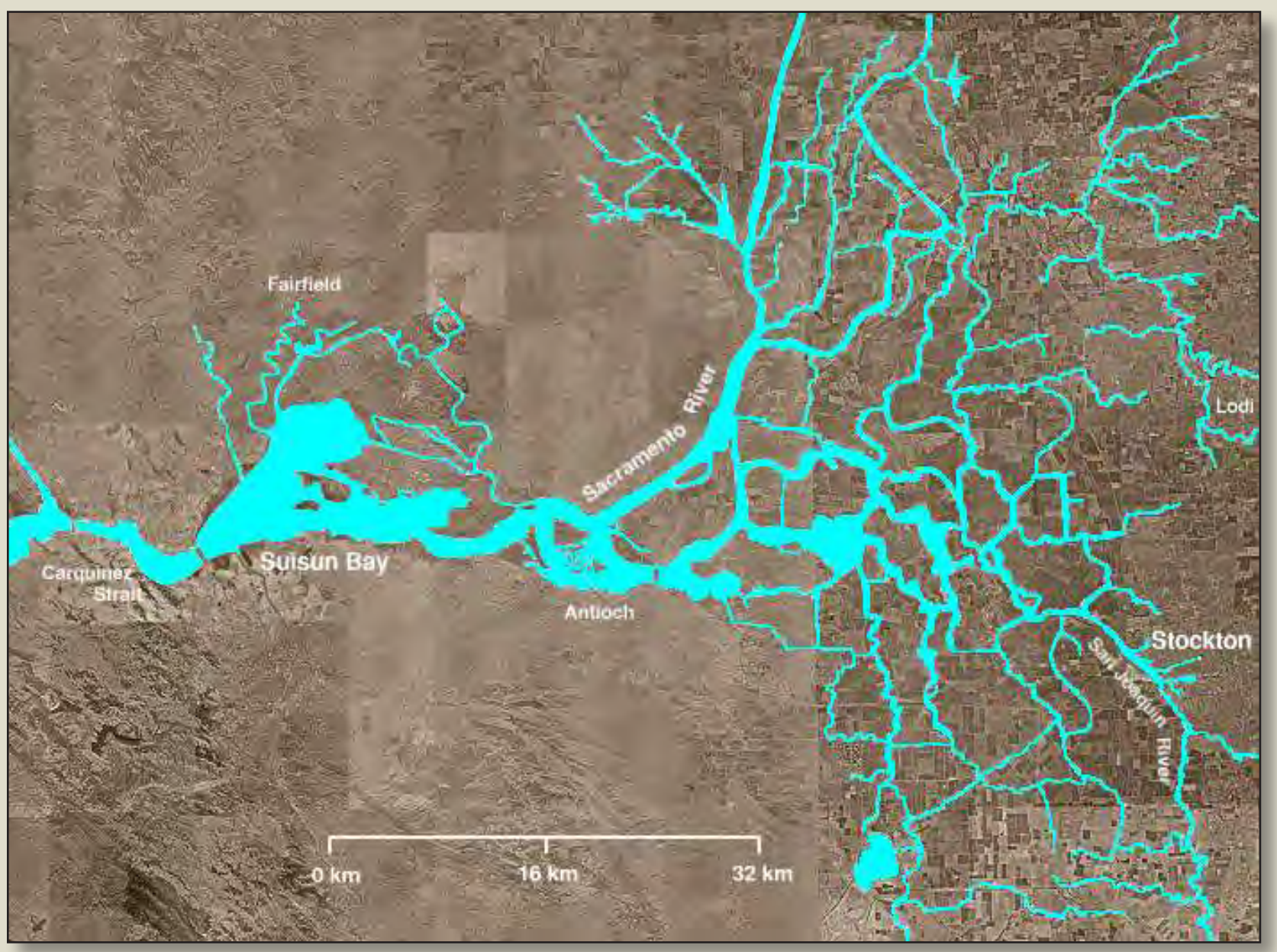

Open-File Report 2019-1125

U.S. Department of the Interior

U.S. Geological Survey 
Cover: Image showing Sacramento River flowing into the SacramentoSan Joaquin River Delta (cover right half of the map image) from the north and the San Joaquin River from the south. Image courtesy of Matthew Trump, licensed under the Creative Commons Attribution-Share Alike 3.0 Unported license. 


\section{Using the STARS Model to Evaluate the Effects of the Proposed Action for the Reinitiation of Consultation on the Coordinated Long-Term Operation of the Central Valley and State Water Project}

By Russell W. Perry, Adam C. Pope, and Vamsi K. Sridharan

Prepared in cooperation with National Oceanic and Atmospheric Administration, National Marine Fisheries Service

Open File Report 2019-1125

U.S. Department of the Interior

U.S. Geological Survey 


\section{U.S. Department of the Interior \\ DAVID L. BERNHARDT, Secretary}

\section{U.S. Geological Survey \\ James Reilly II, Director}

U.S. Geological Survey, Reston, Virginia: 2019

For more information on the USGS-the Federal source for science about the Earth, its natural and living resources, natural hazards, and the environment-visit https://www.usgs.gov/ or call 1-888-ASK-USGS (1-888-275-8747).

For an overview of USGS information products, including maps, imagery, and publications, visit https:/store.usgs.gov.

Any use of trade, firm, or product names is for descriptive purposes only and does not imply endorsement by the U.S. Government.

Although this information product, for the most part, is in the public domain, it also may contain copyrighted materials as noted in the text. Permission to reproduce copyrighted items must be secured from the copyright owner.

Suggested citation:

Perry, R.W., Pope, A.C., and Sridharan, V.K., 2019, Using the STARS model to evaluate the effects of the proposed action for the reinitiation of consultation on the coordinated long-term operation of the Central Valley and State Water Project: U.S. Geological Survey Open-File Report 2019-1125, 31 p. plus appendixes, https://doi.org/10.3133/ofr20191125.

ISSN 2331-1258 (online) 


\section{Contents}

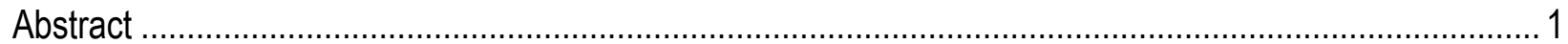

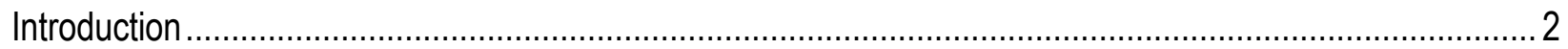

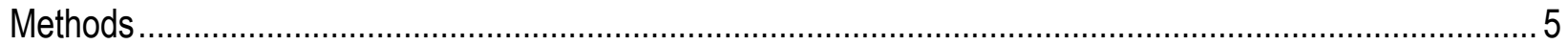

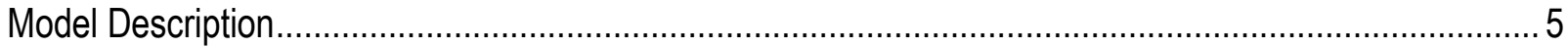

Summary of the Bayesian Mark-Recapture Model.................................................................. 5

STARS: Survival, Travel Time, and Routing Simulation ............................................................. 10

Comparing the Proposed-Action and Continuing-Operations Scenarios ............................................. 11

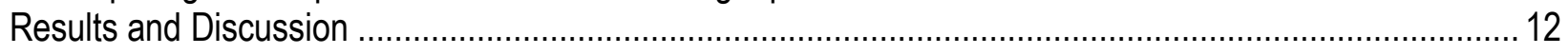

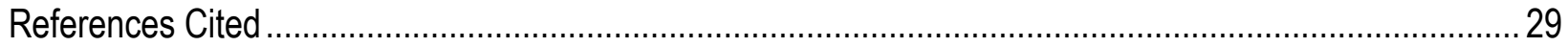

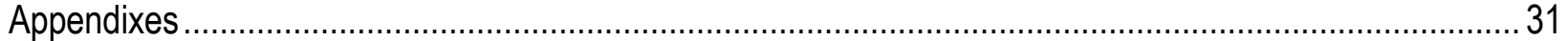

Appendix 1. Simulated Daily Survival by Year, Continuing Operations Compared to Proposed

Action Scenarios, 1922-2003 ....................................................................................................... 31

Appendix 2. Simulated Daily Travel Time by Year, Continuing Operations Compared to

Proposed Action Scenarios, 1922-2003

Appendix 3. Simulated Daily Routing by Year, Continuing Operations Compared to Proposed

Action Scenarios, 1922-2003.

Appendix 4. Simulated Proportion of Fish Entering the Interior Delta by Year Continuing

Operations Compared to Proposed Action Scenarios, 1922-2003

\section{Figures}

Figure 1. Map showing locations of acoustic-telemetry receiving stations (filled black circles) used to detect acoustic-tagged juvenile Chinook salmon as they migrated through the Sacramento-San Joaquin River Delta,

northern California.

Figure 2. Relationships between routing probability and inflow to the Delta as measured at the Sacramento River at Freeport (A2 in fig. 1).

Figure 3. Graphs showing route-specific travel-time distributions of juvenile Chinook salmon at the 5th (top graph) and 95th (bottom graph) percentiles of discharge based on the historical flow record $(8,290$ and 47,910 $\mathrm{ft} 3 / \mathrm{s})$ between Freeport and Chipps Island (see fig. 1), Sacramento-San Joaquin River Delta, northern California. 8

Figure 4. Graphs showing route-specific survival of juvenile Chinook salmon between Freeport and Chipps Island (see fig. 1) through the Sacramento-San Joaquin River Delta, northern California. 
Figure 5. Graphs showing simulated daily river flow and Delta Cross Channel (DCC) gate operations for water year 1979 (top graph), medians of simulated mean daily survival probabilities through the Sacramento-San Joaquin River Delta, northern California (middle graph), and the difference in survival probabilities between the Proposed Action (PA) and Continuing Operation Scenario (COS) scenarios (bottom graph). 15

Figure 6. Graphs showing simulated daily river flow and Delta Cross Channel (DCC) gate operations for water year 1990 (top graph), median of simulated mean daily survival probabilities through the Sacramento-San Joaquin River Delta, northern California (middle graph), and the difference in survival probabilities between the Proposed Action (PA) and Continuing Operation Scenario (COS) scenarios (bottom graph). 16

Figure 7. Graphs showing simulated daily river flow and Delta Cross Channel (DCC) gate operations for water year 1979 (top graph), simulated median daily travel time of juvenile Chinook salmon through the Sacramento-San Joaquin River Delta, northern California (middle graph), and the difference in travel times between the Proposed Action (PA) and Continuing Operation Scenario (COS) scenarios (bottom graph). 17

Figure 8. Graphs showing simulated daily river flow and Delta Cross Channel (DCC) gate operations for water year 1990 (top graph), simulated median daily travel time of juvenile Chinook salmon through the Sacramento-San Joaquin River Delta, northern California (middle graph), and the difference in travel time between the Proposed Action (PA) and Continuing Operation Scenario (COS) scenarios (bottom graph). 18

Figure 9. Graphs showing simulated daily river flow and Delta Cross Channel (DCC) gate operations for water year 1979 (top graph), and stacked line plots showing the daily cumulative migration-route probabilities for the Proposed Action (PA, middle graph) and Continuing Operation Scenario (COS, bottom graph) scenarios, Sacramento-San Joaquin River Delta, northern California. 19 
Figure 10. Graphs showing simulated daily river flow and Delta Cross Channel (DCC) gate operations for water year 1990 (top graph), and stacked line plots showing the daily cumulative migration-route probabilities for the Proposed Action (PA, middle graph) and Continuing Operation Scenario (COS, bottom graph) scenarios, Sacramento-San Joaquin River Delta, northern California. 20

Figure 11. Graphs showing simulated daily river flow and Delta Cross Channel (DCC) gate operations for water year 1979 (top graph), simulated median probability of entering the Interior Delta through the Delta Cross Channel or Georgiana Slough (middle graph), and the difference in routing between the Proposed Action (PA) and Continuing Operation Scenario (COS) scenarios (bottom graph).

Figure 12. Graphs showing simulated daily river flow and Delta Cross Channel (DCC) gate operations for water year 1990 (top graph), simulated median probability of entering the Interior Delta through the Delta Cross Channel or Georgiana Slough (middle graph), and the difference in routing between the Proposed Action (PA) and Continuing Operation Scenario (COS) scenarios (bottom graph).

Figure 13. Boxplots showing the distribution of the probability that through-Delta survival under the Proposed Action (PA) scenario is less than the probability of survival under the Continuing Operation Scenario (COS)....... 23 Figure 14. Boxplots showing the distribution of the probability that the difference in median travel time through the Delta between the Continuing Operation Scenario (COS) and the Proposed Action (PA) scenario is greater than zero. 23

Figure 15. Boxplots showing the distribution of the probability that the difference in being routed into the Interior Delta between the Continuing Operation Scenario (COS) and Proposed Action (PA) scenario is greater than zero. 24

Figure 16. Boxplots of daily median differences in through-Delta survival between the Proposed Action (PA) scenario and Continuing Operation Scenario (COS). 
Figure 17. Daily boxplots of differences in median travel time between the Proposed Action (PA) scenario and Continuing Operation Scenario (COS).

Figure 18. Daily boxplots of differences in routing to the Interior Delta between the Proposed Action (PA) scenario and Continuing Operation Scenario (COS) 25

Figure 19. Daily boxplots of median differences in through-Delta survival rates between the Proposed Action (PA) scenario and Continuing Operation Scenario (COS) by water-year type. 26

Figure 20. Daily boxplots of median differences in median travel times between the Proposed Action (PA) scenario and Continuing Operation Scenario (COS) by water-year type. 27

Figure 21. Daily boxplots of median differences in routing to the Interior Delta between the Proposed Action (PA) scenario and Continuing Operation Scenario (COS) by water-year type. 


\section{Conversion Factors}

Inch/Pound to International System of Units

\begin{tabular}{ccc}
\hline Multiply & By & To obtain \\
\hline acre-foot (acre-ft) & Volume & \\
\hline \multicolumn{1}{c}{1,233} & cubic meter $\left(\mathrm{m}^{3}\right)$ \\
\hline cubic foot per second (ft $/ \mathrm{s})$ & Flow rate & \\
\hline International System of Units to Inch/Pound & 0.02832 & cubic meter per second $\left(\mathrm{m}^{3} / \mathrm{s}\right)$ \\
\hline Multiply & By & To obtain \\
\hline & Length & \\
\hline kilometer $(\mathrm{km})$ & 0.6214 & $\mathrm{mi}(\mathrm{mi})$ \\
\hline
\end{tabular}

\section{Abbreviations}

$\begin{array}{ll}\text { COS } & \text { Continuing Operations Scenario } \\ \text { CVP } & \text { Central Valley Project } \\ \text { DCC } & \text { Delta Cross Channel } \\ \text { DPS } & \text { distinct population segment } \\ \text { DSM2 } & \text { Delta Simulation Model-II } \\ \text { DWR } & \text { California Department of Water Resources } \\ \text { ESA } & \text { Endangered Species Act } \\ \text { MAF } & \text { millions of acre-feet } \\ \text { MCMC } & \text { Markov Chain Monte Carlo } \\ \text { NMFS } & \text { National Marine Fisheries Service } \\ \text { PA } & \text { Proposed Action Scenario } \\ \text { STARS } & \text { Survival, Travel time, And Routing Simulation } \\ \text { SWP } & \text { State Water Project } \\ \text { USFSW } & \text { U.S. Fish and Wildlife Service } \\ \text { USBR } & \text { U.S. Bureau of Reclamation } \\ \text { USGS } & \text { U.S. Geological Survey } \\ \text { WY } & \text { water year } \\ \text { WYI } & \text { water-year index }\end{array}$


This page intentionally left blank 


\title{
Using the STARS Model to Evaluate the Effects of the Proposed Action for the Reinitiation of Consultation on the Coordinated Long-Term Operation of the Central Valley and State Water Project
}

\author{
By Russell W. Perry ${ }^{1}$, Adam C. Pope ${ }^{1}$, Vamsi K. Sridharan ${ }^{2}$
}

\section{Abstract}

In 2016, the U.S. Bureau of Reclamation (USBR) and California Department of Water Resources requested a reinitiation of consultation under Section 7 of the Endangered Species Act on the coordinated long-term operations of the Central Valley and State Water Projects. This resulted in a Biological Assessment released by USBR in 2019. In its analysis of the Biological Assessment for its Biological Opinion on the proposed action, the National Marine Fisheries Service (NMFS) requested assistance from the U.S. Geological Survey to describe the effect of the proposed action on juvenile Chinook salmon (Oncorhynchus tshawytscha) populations migrating through the Sacramento-San Joaquin River Delta (henceforth called "the Delta"). Therefore, in this report we analyzed an 82-year time series of simulated river flows and Delta Cross Channel (DCC) gate operations under two scenarios constructed for the Biological Assessment: the proposed-action (PA) scenario and the continuing-operations scenario (COS).

To evaluate the proposed action, we used the STARS model (ㅁurvival, Travel time, And

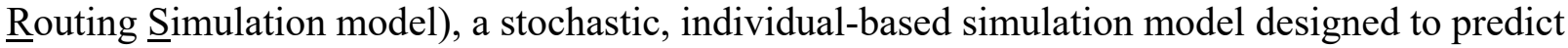
survival of a cohort of fish that experiences variable daily river flows as the fish migrate through the Delta. The STARS model uses parameter estimates from a Bayesian mark-recapture model that jointly estimates travel time and survival in eight discrete reaches of the Delta and migration routing at two key river junctions.

By applying the STARS model to the two 82-year scenarios, we found that the proposed action had negative effects on survival, travel time, and routing in October-December but positive effects in April-June. In October-December, there was a high probability that survival in the PA scenario was less than that in the COS, and that travel time and routing to the Interior Delta for the PA scenario was greater than that for the COS. The magnitude of the difference in survival between scenarios was larger in some years than in others. For example, we quantified that survival under the PA scenario was 10 percent lower than under the COS in 25 percent of the water years from October through December. During this period, inflow to the Delta tended to be lower under the PA scenario, and the DCC gate was open more frequently under the PA scenario than during the COS. Lower inflow reduces survival, and more frequent operation of the DCC gate 1) increases the proportion of fish entering the Interior Delta, where survival is low, and thus 2) reduces survival in the Sacramento River in reaches downstream of the DCC. In contrast, during the period April-June, survival was higher, travel times were lower, and routing to the Interior Delta was lower under the PA scenario relative to

\footnotetext{
${ }^{1}$ U.S. Geological Survey.

${ }^{2}$ University of California, Santa Cruz.
} 
the COS, although the magnitude of the increase in survival was relatively small in most years (less than a 3-percent difference in survival). This difference between scenarios was driven by higher river flows in some years under the PA scenario relative to the COS. Overall, the differences in survival, travel time, and routing distance between the two operational scenarios were primarily driven by the timing and magnitude of the annual high river flows.

\section{Introduction}

The U.S. Bureau of Reclamation (USBR) and the California Department of Water Resources (DWR) have joint responsibility for the coordinated long-term operations of the Central Valley Project (CVP) and State Water Project (SWP). The CVP and SWP are a system of reservoirs, dams, and hydraulic and water-conveyance structures in the California Central Valley. These structures have been installed for the purposes of generating power and delivering water for agricultural and domestic use, while providing flood protection and protecting water quality for downstream users (USBR, 2019). Because the Sacramento and San Joaquin watersheds harbor several critically endangered species listed under the Endangered Species Act (ESA), USBR has undertaken consultation in accordance to the requirements of Section 7 of the ESA with the U.S. Fish and Wildlife Service (USFWS) and National Marine Fisheries Service (NMFS). Most recently, NMFS issued a Biological Opinion in 2009 (NMFS, 2009) concluding that the long-term operations of the CVP and SWP were likely to jeopardize the continued existence of the Sacramento River Winter-Run Chinook salmon and the Central Valley Spring-Run Chinook salmon (Oncorhynchus tshawytscha), the California Central Valley steelhead (Oncorhynchus mykiss), the Southern distinct population segment (DPS) of the North American green sturgeon (Acipenser medirostris), and the Southern resident DPS of the killer whale (Orcinus orca). In 2016, USBR and DWR requested the reinitiation of consultation on the coordinated long-term operation of the CVP and SWP, resulting in a Biological Assessment released in 2019 (USBR, 2019).

The Biological Assessment describes a proposed action that focuses on a core water operation that would allow operation of the CVP and SWP for water supply and other project purposes, while also avoiding jeopardy of ESA-listed species. In its analysis of the Biological Assessment for the Biological Opinion on the proposed action, NMFS requested assistance of the U.S. Geological Survey in understanding the effect of the proposed action on juvenile Chinook salmon populations migrating through the Sacramento-San Joaquin River Delta (henceforth, "the Delta"). Over the past decade, the U.S. Geological Survey (USGS) has developed detailed statistical analyses of acoustic telemetry data on the migration of juvenile salmon to determine how river flow, tides, and Delta Cross Channel (DCC) gate operations interact to direct the routing and survival of juvenile Chinook salmon migrating through the Delta. Therefore, in this report we analyze an 82-year time series of simulated river flows and DCC gate operations under two scenarios constructed for the Biological Assessment: the proposed action scenario (PA) and the continuing operations scenario (COS).

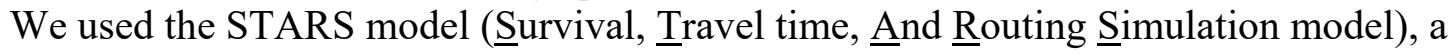
stochastic, individual-based simulation model designed to predict survival of a cohort of fish that experience varying daily river flows as they migrate through the Delta (fig. 1). The parameters on which the STARS model is based are derived from a Bayesian mark-recapture model that jointly estimated reach-specific travel time, migration routing, and survival of juvenile Chinook salmon. This model extended the work of Perry and others (2010) to estimate the effect of the Delta Cross Channel (see $\mathrm{C}_{4}$ in fig. 1) and Delta inflows as measured in the Sacramento River at Freeport (U.S. Geological Survey [USGS] streamgage 11447650; see $A_{2}$ in fig. 1) on survival, routing, and travel time of juvenile Chinook salmon in eight reaches of the Delta (fig. 1). Perry and others (2018) determined that the median travel time was related to the inflow in all reaches of the Delta. In contrast, survival was strongly related to inflow in only three of eight reaches (reaches 3, 4 and 5 in fig. 1). In these three 
reaches that exhibited strong inflow-survival relationships, river flows changed from tidally influenced, bidirectional flow at low net inflow to unidirectional downstream flow as net inflows increased and tidal forcing was dampened. Thus, the flow-survival relations in these three reaches caused route-specific survival through the Delta to increase with flow, yet fish that entered the Interior Delta (reach 8 in fig. 1) through Georgiana Slough or the DCC experienced lower route-specific survival than fish that entered through other migration routes. In addition, Perry and others (2018) determined that the proportion of fish entering the Interior Delta increased as 1) inflows decreased below about $25,000 \mathrm{ft}^{3} / \mathrm{s}$ or 2) the DCC gate was opened (Perry and others, 2018). These mechanisms increase the proportion of fish traveling along low-survival migration routes and thereby further reducing overall survival through the Delta.

Although the effect of river flow on overall survival through the Delta has been established for some time (Newman and Rice, 2002; Newman, 2003; Perry, 2010), our goal was to use the recently developed survival, travel-time, and routing relationships (Perry and others, 2018) to better understand the potential magnitude of the effect of the proposed action on juvenile-salmon survival, routing, and travel time. Because our model incorporates the effects of river flow and DCC gate operation on juvenile Chinook routing, travel time, and survival, our analysis can be used to identify mechanisms by which operations affect overall survival throughout the Delta. One drawback, however, is that the statistical model of Perry and others (2018) did not include water exports (that is, water pumped out of the Southern Delta). Thus, the modeling results in this report are insensitive to any difference in exports among the scenarios being considered. Although we are currently developing models that include export effects, those models were not available in time to use for this analysis. 


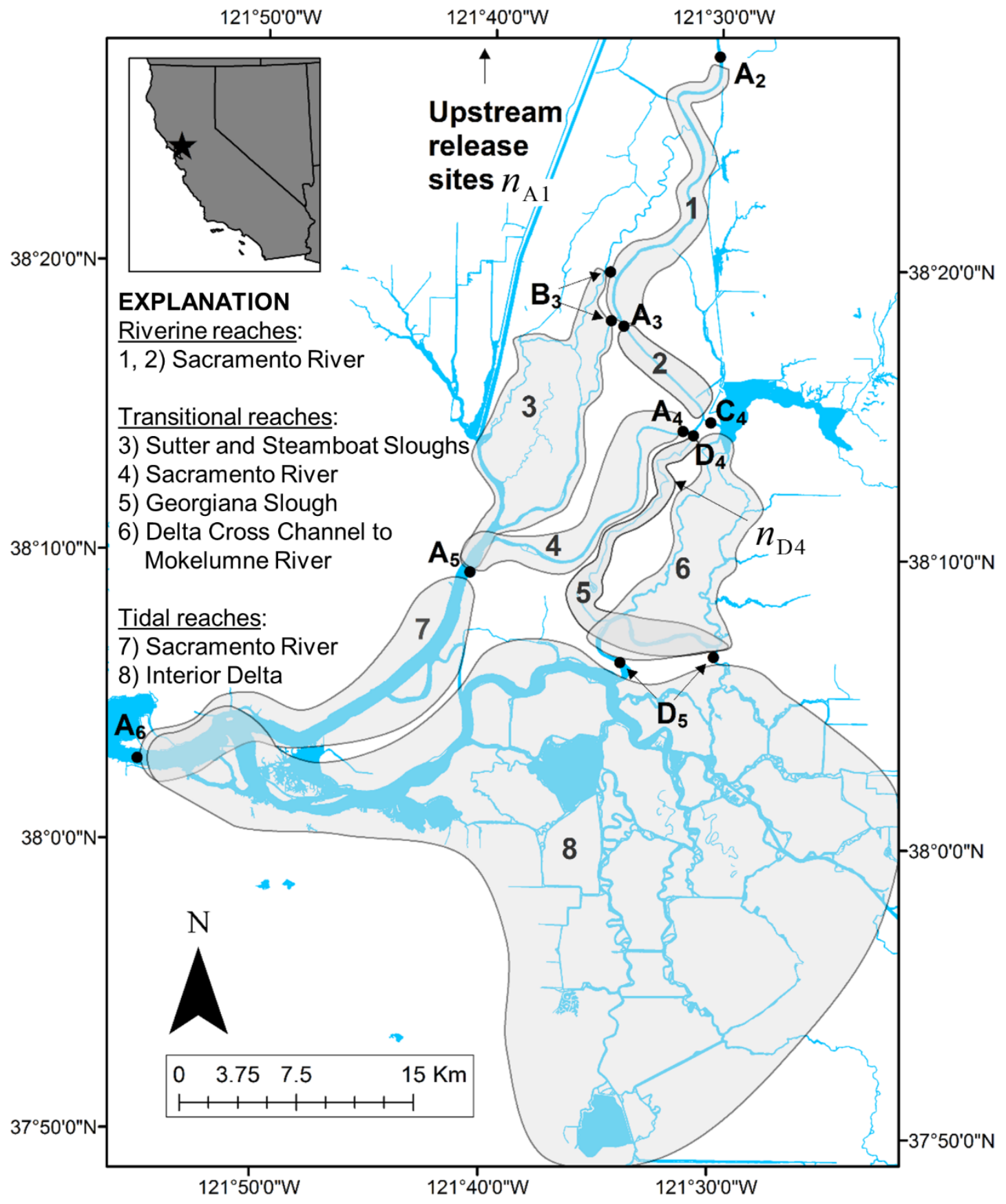

Figure 1. Map showing locations of acoustic-telemetry receiving stations (filled black circles) used to detect acoustic-tagged juvenile Chinook salmon as they migrated through the Sacramento-San Joaquin River Delta, northern California. Telemetry stations are labeled by migration route (A, Sacramento River; B, Sutter and Steamboat Sloughs; C, Delta Cross Channel; D, Georgiana Slough) and sampling occasion (1-8, sites 1 and 7 not shown on map). These telemetry stations divide the Delta into eight discrete reaches (shown by numbered shaded regions) with an additional reach upstream of telemetry station $A_{2}$ (Reach 0 ) used as an acclimation reach to allow fish to recover from post-release handling. Route-specific survival begins at $A_{2}$ (Freeport) and ends at $A_{6}$ (Chipps Island). Release sites are labeled as $n_{\mathrm{A} 1}$ and $n_{\mathrm{D} 4}$. 


\section{Methods}

\section{Model Description}

Here we provide a summary of the STARS model and the associated Bayesian mark-recapture model we used to simulate survival, travel time, and migration routing.

\section{Summary of the Bayesian Mark-Recapture Model}

The STARS model uses parameter estimates from a Bayesian mark-recapture model that jointly estimates travel time and survival in eight discrete reaches of the Delta and migration routing at two key river junctions (fig. 1, stations $\mathrm{A}_{3}$ and $\mathrm{B}_{3}$ and stations $\mathrm{A}_{4}, \mathrm{D}_{4}$, and $\mathrm{C}_{4}$ ). The data for the analysis consisted of 2,170 acoustic-tagged late-fall Chinook salmon released during a 5-year period (2007-11) over a wide range of Sacramento River inflows (6,816-76,986 $\mathrm{ft}^{3} / \mathrm{s}$ at Freeport (station $\left.\mathrm{A}_{2}\right)$ ). This analysis was based on acoustic telemetry data from several published studies in which interested readers can find more detail (Perry and others, 2010, 2013; Michel and others, 2015).

Although numerous studies have identified a relation between Delta inflows and survival at the Delta-wide scale, the goal of the Perry and others (2018) analysis was to quantify how the flowsurvival relation varied spatially among different regions of the Delta. To quantify the reach-specific relation between river inflows and survival, they used time-varying individual covariates in which an individual's covariate value was defined as the daily mean flow of the Sacramento River at Freeport and at the DCC gate position on the day that $i$ th fish entered the $n$th reach. Because of missing covariate values for undetected fish, they implemented the multistate mark-recapture model of Perry and others (2010) by using a complete data likelihood approach in a Bayesian framework (King and others, 2010). To account for missing covariate values, they jointly modeled reach-specific travel times, routing, and survival. Their analysis used the estimated parameters of a log-normal travel-time distribution for each reach to estimate travel times of undetected fish, which in turn allowed missing covariate values to be based on the estimated arrival time in a given reach. Markov Chain Monte Carlo (MCMC) techniques were used to integrate over the missing covariate values by drawing missing travel times on each iteration of the Markov chain.

Perry and others (2018) found that the proportion of fish using each migration route depended on river flow, but the direction of the relationship differed among river junctions (fig. 2). At the junction of the Sacramento River with Sutter and Steamboat Sloughs ( $B_{3}$ in fig. 1), the probability of fish entering Sutter and Steamboat sloughs increased with river flow. In contrast, at the junction of the Sacramento River with Georgiana Slough ( $\mathrm{D}_{4}$ in fig. 1) and the DCC (C4 in fig. 1), the probability of fish entering Georgiana Slough decreased with increasing flow. Opening the DCC gates decreased the probability of entering Georgiana Slough but increased the proportion of fish entering the Interior Delta through both the DCC and Georgiana Slough.

In their analysis, Perry and others (2018) also identified a negative relation between river inflows and median travel times in all reaches of the Delta (fig. 3), but the nature of the relationship between flow and survival varied among reaches (see fig. 6 in Perry and others, 2018). In the upper reaches of the Delta (reaches 1 and 2 in fig. 1), survival was consistently high regardless of inflow, whereas in the strongly tidal reaches (reaches 7 and 8 in fig. 1), there was no significant relation between river inflows and reach-specific survival despite a relation between inflow and travel time. The strongest positive flow-survival relations were identified in the three reaches that transition from river-dominated to tidally dominated flows (reaches 3,4 , and 5 in fig. 1). 
The product of reach-specific survival for a given migration pathway between Freeport $\left(\mathrm{A}_{2}\right.$ in fig. 1) and Chipps Island ( $\mathrm{A}_{6}$ in fig. 1) yields the probability of surviving through each migration route at a given river discharge. Route-specific survival for all routes increased with river discharge but approached an asymptote, leveling off at about 0.75 for the Sacramento River and Sutter and Steamboat Sloughs, and at about 0.35 for fish entering Georgiana Slough when river discharges increased to more than about $30,000 \mathrm{ft}^{3} / \mathrm{s}$ (fig. 4). The reach-specific survival relations indicate that the asymptote in route-specific survival was driven by the survival in the strongly tidal reaches (reaches 7 and 8) because survival for all other reaches approached 1 as flow increased but remained constant with flow for the strongly tidal reaches. Expected travel-time distributions for each migration route decreased as river flow increased, with migration routes leading to the Interior Delta (Georgiana Slough and the Delta Cross Channel) having longer travel times than other routes (fig. 3).

The statistical relationships arising from the fitting of the Bayesian mark-recapture model reflect the expected patterns based on the hydrodynamics of the Delta. The routing patterns are consistent with what would be expected because of the structure of the water velocity across the water column and fish distributions in the channel cross section (Perry and others, 2014; Perry and others, 2015). Increasing inflow to the Delta dampens tidal fluctuations and increases water velocities, which in turn increase juvenile-salmon migration rates (Zabel, 2002). The flow-dependent patterns of survival rates can be qualitatively explained by the interplay between the flow, the channel topography and morphology, tidal dynamics, and predator-encounter rate (Perry and others, 2018). Thus, although the model is based on statistical relationships, the patterns in survival, travel time, and routing predicted by the STARS model are largely consistent with our expectations based on the physical principles of hydrodynamics. 


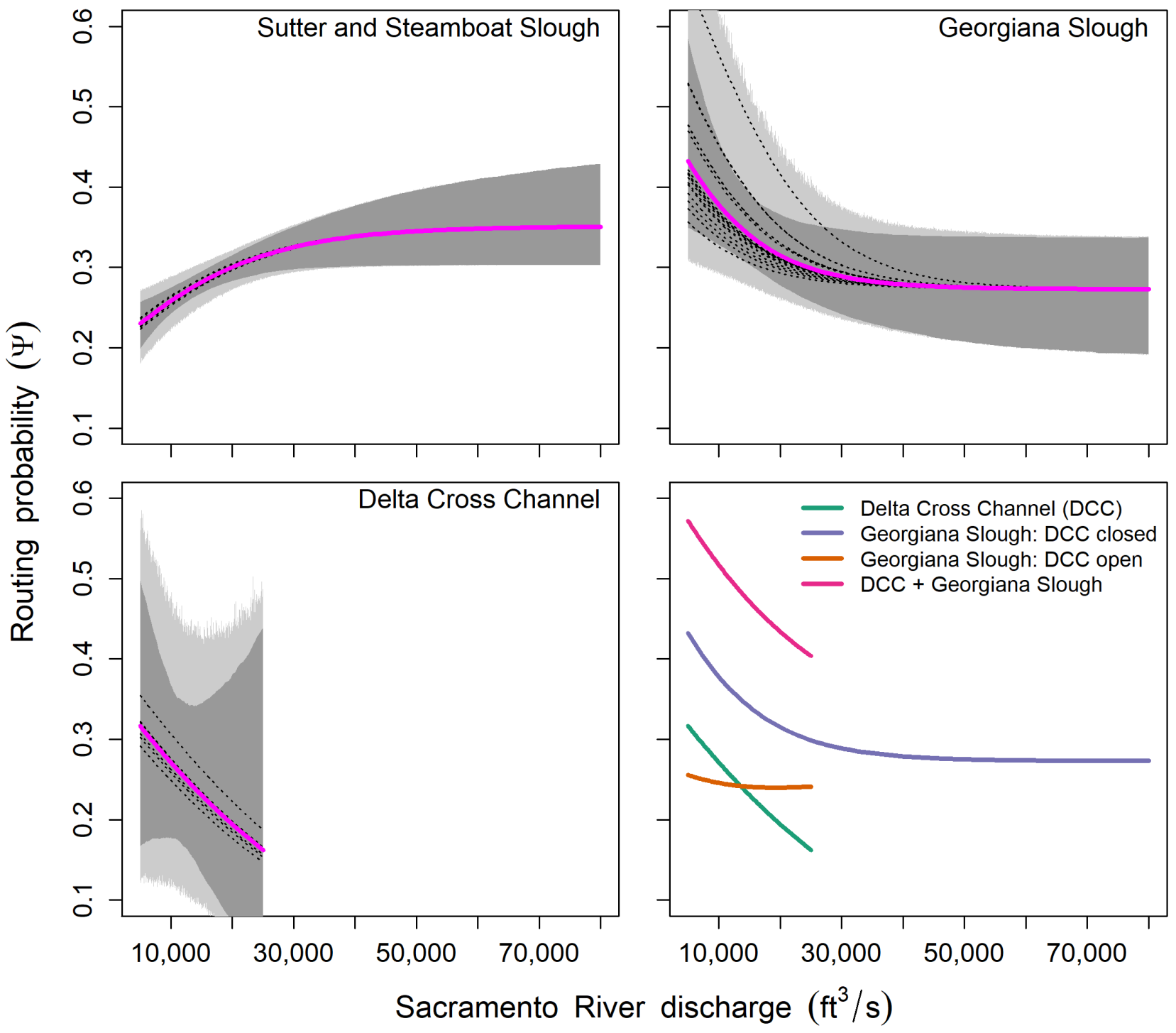

Figure 2. Relationships between routing probability and inflow to the Delta as measured at the Sacramento River at Freeport (A2 in fig. 1). Routing probability is defined as the probability of a fish entering a given migration route conditional on surviving to the entry point of that route. The lower right panel shows the effect of Delta Cross Channel (DCC) gate position on routing probabilities at the junction of the Sacramento River, Delta Cross Channel, and Georgiana Slough (A4, C4, and D4 in fig. 1) plotted at the posterior median of the parameters. Other panels show mean routing relationships (solid heavy magenta line), random-effects estimates for each release group (dotted lines), 95-percent credible interval about the mean relationship (dark gray region), and 95-percent confidence interval among release groups (light gray region). 


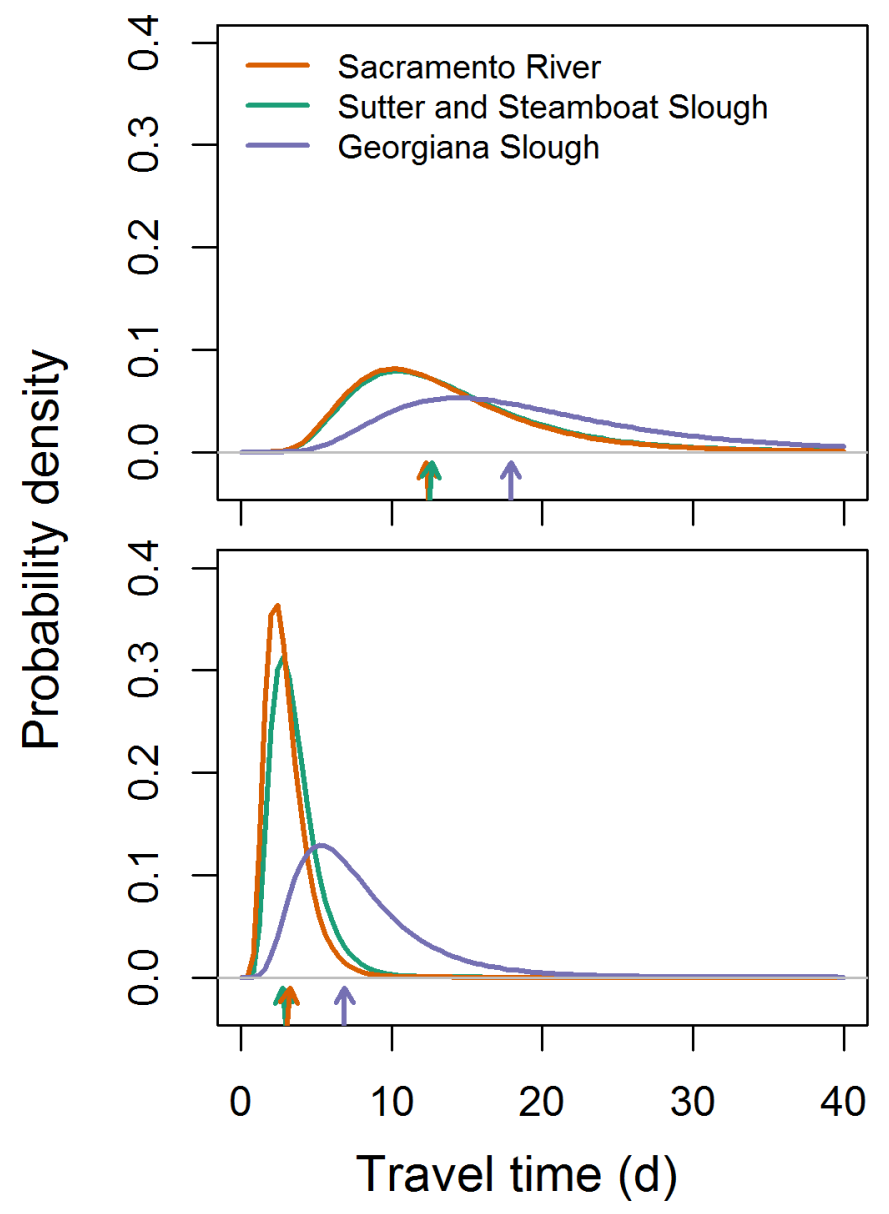

Figure 3. Graphs showing route-specific travel-time distributions of juvenile Chinook salmon at the 5th (top graph) and 95th (bottom graph) percentiles of discharge based on the historical flow record (8,290 and $47,910 \mathrm{ft} 3 / \mathrm{s}$ ) between Freeport and Chipps Island (see fig. 1), Sacramento-San Joaquin River Delta, northern California. Graphs were based on posterior medians of parameters for reach-specific travel-time distributions and the assumption that the Delta Cross Channel gates are closed. Colored arrows show the median travel time for each migration route. $d$, days 


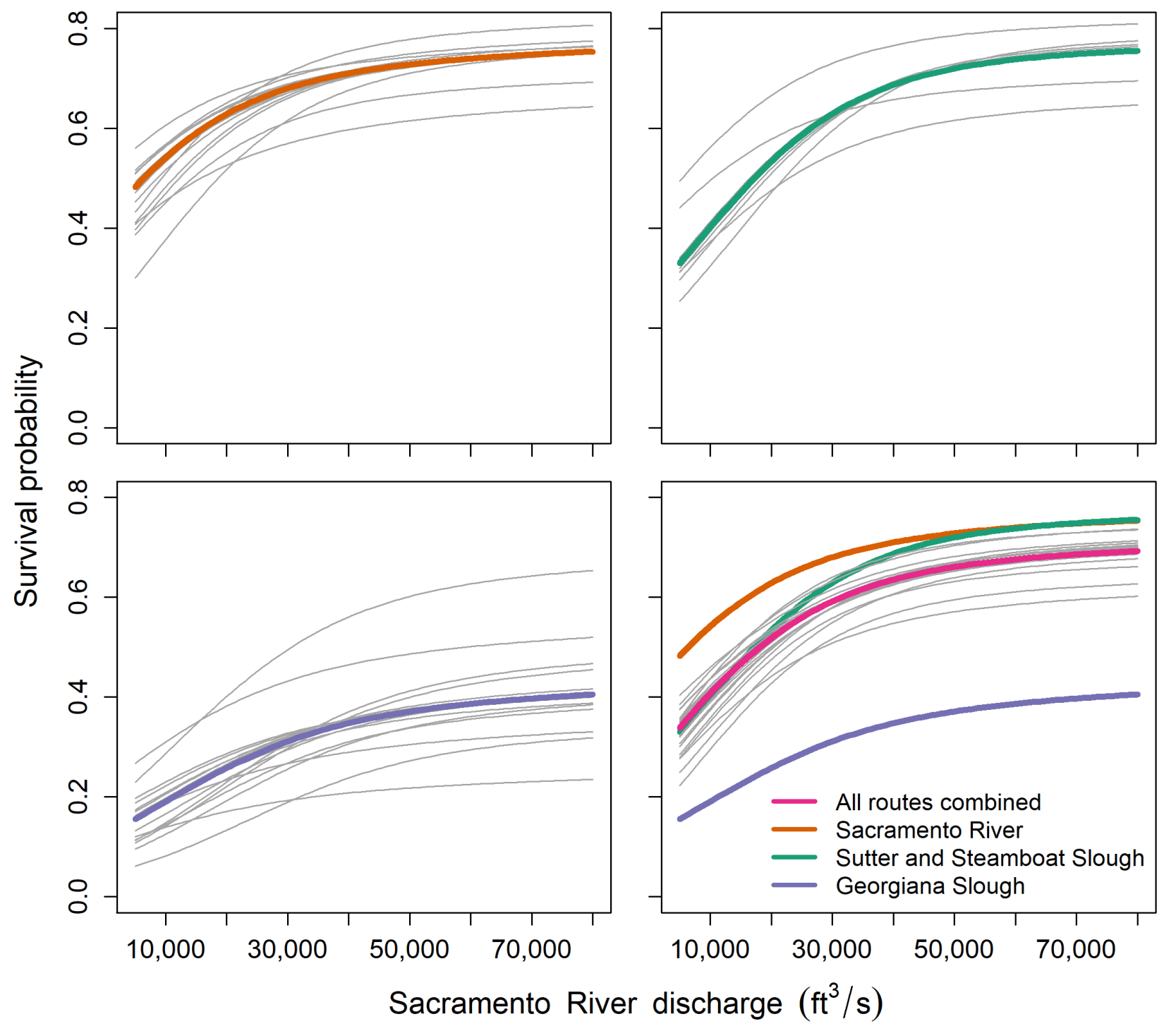

Figure 4. Graphs showing route-specific survival of juvenile Chinook salmon between Freeport and Chipps Island (see fig. 1) through the Sacramento-San Joaquin River Delta, northern California. Route-specific survival probabilities based on posterior-median parameter values were calculated as the products of reachspecific survival probabilities for reaches that trace each unique migration route through the Delta (shown for closed Delta Cross Channel gates). Top graphs and bottom left graph show the mean relation for each route, with thin gray lines showing the random-effect estimates for each release group. Bottom right graph compares the route-specific survival probabilities and includes survival for all routes combined. $\mathrm{ft}^{3} / \mathrm{s}$, cubic feet per second. 


\section{STARS: Survival, Travel Time, and Routing Simulation}

To simulate survival, travel time, and routing, we used the results from the Bayesian markrecapture model of Perry and others (2018). To incorporate measures of uncertainty in our simulations, we used the joint posterior distribution of the survival, routing, and travel-time parameters from the Bayesian analysis. Uncertainty was propagated by doing one simulation for each MCMC draw forming the joint posterior distribution of the parameters.

Random-effect terms in this model estimated the deviation of each release cohort from the average survival, routing, and travel-time relations; however, because we were interested in simulating new cohorts of fish, we drew new random effects for each posterior draw from a normal distribution with mean 0 and standard deviations of $\xi_{S}, \xi_{\Psi}$, and $\xi_{\mu}$ (see Perry and others, 2018, for more detail). In this way, each draw of the joint posterior distribution represents a possible state of nature in which river flow and DCC gate operations affect travel time, routing, and survival of a given cohort of fish. When comparing alternative scenarios (PA and COS), we used the same set of random-effect draws for both scenarios because we envisioned that the same cohort of fish was migrating through the Delta but under two possible alternative operational scenarios.

Given a daily time series of river flow and DCC gate operations, the STARS model simulates survival, migration routing, and travel time as follows (see Perry and others (2018) for the mathematical expressions associated with this algorithm):

1. Select parameter set $i$ from the joint posterior distribution.

2. Initiate the simulation with 1,000 fish at Freeport on day $t$.

3. Calculate survival in reach 1 given discharge on day $t$ and parameter set $i$.

4. Determine individual travel times through reach 1 from a lognormal distribution in which the mean of the distribution depends on parameter set $i$ and discharge on day $t$. This yields a distribution of individual arrival times at the junction of Sutter and Steamboat Sloughs and the Sacramento River ( $\mathrm{A}_{3}$ and $\mathrm{B}_{3}$ in fig. 1).

5. Next, draw the route taken by each fish by using a Bernoulli distribution where the probability of entering Sutter and Steamboat Sloughs is a function of parameters set $i$ and discharge on the day when each fish arrives at the junction.

6. Calculate the survival probability of each individual fish in the next reach downstream given the discharge on the day when each fish entered the reach.

7. Now, draw travel times for each individual fish for the next downstream reach given the flows on the day each fish entered the reach.

8. For fish remaining in the Sacramento River, draw the route taken by fish at the junction of the Sacramento River with the DCC and Georgiana Slough $\left(\mathrm{A}_{4}, \mathrm{C}_{4}\right.$, and $\mathrm{D}_{4}$ in fig. 1$)$ from a multiple Bernoulli distribution in which the probability of fish entering each route depends on the position of the DCC gates and discharge on the day each fish arrives at the junction.

9. Repeat steps 4 and 6 for all remaining reaches.

10. Repeat steps $2-9$ for all days in the daily time series.

11. Repeat steps 1-10 for all iterations of the joint posterior distribution.

This simulation procedure yields a posterior predictive distribution of reach-specific survival probabilities, reach-specific travel times, and routing probabilities for a cohort of 1,000 individual fish entering the Delta at Freeport on each day of a daily time series. By using this approach, our simulation emulated the effects of daily flow variation on through-Delta survival, routing, and travel time for a cohort of fish that entered the Delta on a given day. For example, although two cohorts may enter the Delta under identical flows at Freeport, the survival probability and travel times of these cohorts would differ if one cohort entered during an ascending hydrograph and another cohort entered 
during a descending hydrograph. To see an implementation of the STARS model, we encourage readers to visit National Oceanic and Atmospheric Administration's Central Valley Acoustic Tagging Website, where the STARS model is currently being used to simulate travel time, survival, and routing in real-time for the current water year (https://oceanview.pfeg.noaa.gov/shiny/FED/CalFishTrack/).

\section{Comparing the Proposed-Action and Continuing-Operations Scenarios}

To understand the effect of the proposed action on survival, routing, and travel time of juvenile late-fall Chinook salmon, we simulated travel time, survival, and migration routing by using an 82year time series of river flows and DCC gate operations under each scenario. Monthly river flows and DCC gate operations were simulated by using the CalSim II water-operations model and then disaggregated to daily river flows and gate operations for inputs into the Delta Simulation Model II (DSM2), a one-dimensional hydrodynamic model of the Delta. For more details on how the simulated river operations were constructed, interested readers should consult the Biological Assessment (U.S. Bureau of Reclamation, 2019). Because our model relied on measurements of daily inflows to the Delta and daily DCC-gate operations, we constructed the daily river flows and DCC-gate operations as inputs for DSM2 for input to the STARS model. The STARS model produced through-Delta survival probabilities, migration routing, and travel-time distributions for a cohort of fish entering the Delta at Freeport on each day of the 82-year daily time series for each scenario.

We summarized the simulation output to provide useful statistics describing each daily cohort:

- The daily proportion of fish using each unique migration route.

- The daily proportion of fish entering the Interior Delta via the DCC and Georgiana Slough.

- Overall survival through the Delta, calculated as the mean survival probability of all individuals that entered the Delta on day $t$. Because routing for each individual was randomly drawn at each river junction, the mean survival is weighted by the proportion of fish that used each route.

- Median travel time over all routes for individuals that entered the Delta on day $t$. Median travel time was calculated by first adding reach-specific travel times for each individual between Freeport and Chipps Island and then calculating the exponent of the mean of the logarithms of the travel times.

To display model output, we generated four annual graphs:

- daily flows for each scenario,

- daily overall through-Delta survival $\left(S_{\text {Delta }}\right)$ and median travel times,

- daily routing probabilities, and

- the median travel-time differences among scenarios in $S_{\text {Delta, }}$ and the proportion of fish entering the Interior Delta.

For these graphs, we plotted the posterior medians and 80-percent credible intervals of the differences between scenarios. We presented data in the body of the report for two water years ${ }^{3}$ to represent model output; graphs for all 82 years are provided in appendixes $1-4$.

To summarize the 82-year time series, we used boxplots to examine the probabilities and magnitudes of differences in the daily survival rates, travel times between scenarios, and routing to the Interior Delta. For survival, we calculated the probability that survival for the PA scenario was less than for the COS. This probability was calculated as the fraction of the posterior distribution of the

\footnotetext{
${ }^{3}$ The 12-month period from October 1, for any given year, through September 30, of the following year. The water year is designated by the calendar year in which it ends.
} 
daily difference in survival between scenarios that was less than 0 . For travel time and routing to the Interior Delta, we calculated the probability that travel time or routing for the PA scenario was greater than under the COS. This approach produced a daily time series of probabilities for the 82-year simulation, which we summarized by using boxplots for each day of the year.

To examine the magnitudes of the differences in survival, travel time, or routing to the Interior Delta, we used boxplots to display the distributions of posterior median differences for all years combined and by water-year (WY) type. DWR uses five classifications for water-year type in the Sacramento Valley that are based on the water-year index value (WYI) in millions of acre-feet:

1. W=Wet, WYI greater than or equal to $(\geq) 9.2$;

2. $\mathrm{AN}=\mathrm{Above}$ Normal, greater than or equal to 7.8 and less than $(\leq) \mathrm{WYI}<9.2$;

3. $\mathrm{BN}=$ Below Normal, $6.5 \leq \mathrm{WYI}<7.8$;

4. $\mathrm{D}=$ Dry, $5.4 \leq \mathrm{WYI}<6.5$; and

5. $\mathrm{C}=$ Critical, WYI $<5.4$ (Kapahi and others, 2006).

\section{Results and Discussion}

Detailed results for survival, travel time, and routing for two water years-WYs 1979, a belownormal water year, and 1990, a critically dry water year-were shown. Drier-than-normal years were chosen because these water-year types are more likely to lead to lower river flows, longer travel times, and lower survival rates for juvenile salmon. Results for each of the 82-year time series are in Appendix 1. We first focused on describing river flows and gate operations. For both water years, we noticed sharp monthly changes in simulated daily river discharge, which is quite different from actual river flows (figs. 5 and 6). The steps are also apparent in most other years (Appendix 1). The disaggregation from monthly to daily data involved using splines to transition from one month to the next to prevent model instabilities, thereby preserving the pattern of monthly steps in river flows (written commun., 9 May 2019, Steve Micko, Jacobs Engineering Group).

In WY 1979, 1990, and other water years (Appendix 1), we noticed differences in DCC gate operation among scenarios during the October-December period. Although both the PA scenario and COS operate under the same DCC control rule, different flows for each scenario trigger DCC gate closures differently for each scenario. The number of gate-closure days each month between October 1 and December 14 is determined in CalSim II by using an empirical relationship between monthly average flow and the number of days per month that the flow at Wilkins Slough (USGS streamgage 11390500 ) exceeds $7,500 \mathrm{ft}^{3} / \mathrm{s}$ (ICF International, 2016). Because the specific days of gate closure in each month are not specified by CalSim II, DSM2 inputs were structured to assume that gate openings occur on consecutive days at the beginning of each month, and that closures occur at the end of each month (see figs. 5 and 6 as examples). For example, in 1979, lower Delta inflows at Freeport during November are likely associated with lower flows at Wilkins Slough, thereby triggering fewer gateclosure days and allowing the DCC to remain open longer under the PA scenario relative to the COS (fig. 5).

For WY 1979, through-Delta survival of fish under the PA scenario was considerably lower than the COS during October-November because of differences in discharge and the operation of the DCC (fig. 5). During this period, the largest difference in survival (about 14 percentage points) occurred during mid-November, when the DCC was open under the PA scenario but closed under the COS, and when discharge for the PA scenario was lower than for the COS. Patterns of travel time through the Delta were the opposite of patterns of survival, with longer median travel times under the PA scenario during October-November (fig. 7). Owing to differences in both flow and DCC operation, a higher proportion of fish entered the Interior Delta via Georgiana Slough and the DCC under the PA scenario than under the COS (figs. 9 and 11). In contrast, for 1990, a critically dry year, discharge rates 
and DCC operations were similar in October-December, leading to small differences in survival (fig. 6), travel time (fig. 8), or routing (figs. 10 and 12).

For WY 1979, differences in through-Delta survival between scenarios were caused by (1) the underlying flow-survival relationships, (2) differences in survival among routes, and (3) differences in routing that shifted fish between high- and low-survival routes. For example, under the PA scenario during October-November, simulations indicated that a higher proportion of fish entered the DCC (fig. 9) under the COS, which increased the proportion of fish experiencing low survival (fig. 4) and increased travel times (fig. 7). During November-December, flows for the PA scenario were lower than for the COS, which further increased the proportion of fish entering the Interior Delta (fig. 11), in turn exposing a higher fraction of fish to lower survival in the Interior Delta (fig. 4). Furthermore, an open DCC gate reduced flows in the Sacramento River downstream of the DCC, reducing survival of salmon that remained in the Sacramento River (Perry and others, 2018).

For both WYs 1979 and 1990, survival was slightly higher under the PA scenario during the months of May and June owing to higher flows under the PA scenario relative to COS (figs 5 and 6). During this period, higher flows reduced travel times (figs. 7 and 8) and slightly reduced entrainment into the Interior Delta (for the PA scenario, figs. 11 and 12). During the remainder of the year (January-April), there was essentially no difference in river flow or DCC gate operation, leading to no differences in survival, travel time, or routing (figs. 6-12). Detailed graphs for each water year indicate seasonal patterns similar to those for WYs 1979 and 1990 (appendixes 1-4).

Summaries of the 82-year simulation indicated consistent seasonal patterns between scenarios, reflecting seasonal differences in operation under each scenario. The simulations indicated a median probability near one that survival probabilities for the PA scenario were less than for the COS between mid-October and late November (fig. 13). In mid-November, the 25 th percentile was about 0.8 , indicating that 75 percent of the years had an 80-percent probability or greater that survival under the PA scenario was less than the COS. Similar patterns are visible in probability plots of travel time (fig. 14) and routing (fig. 15) during this period. In contrast, during May through mid-June, there was a very low probability of survival under the PA scenario being less than under the COS. For example, the median probability was near zero, indicating a very low probability of survival with the PA scenario being less than the COS in half the years. In mid-May, the 75 th percentile was about 0.1 , indicating that 75 percent of water years had a 10-percent probability or less that survival under the PA scenario was less than COS. Similar probability patterns occurred with travel time (fig. 14) and routing (fig. 15) during this period. For January-April, there was very little difference between the PA scenario and the COS in survival, travel time, or routing to the Interior Delta.

Boxplots of the median differences between scenarios revealed seasonal patterns in the magnitudes of the differences in survival, routing, and travel time. During mid-October-midNovember, the median survival difference between the PA scenario and COS was about 0.02 (fig. 16). Although the median difference was small, the 25 th percentile approached -0.10 in early November, indicating that survival under the PA scenario was more than 10 percentage points lower than under the COS in 25 percent of the water years. Similar patterns occurred with median travel times (fig. 17) and routing into the Interior Delta (fig. 18), except in the opposite direction of survival. For the period of mid-April-June, the 25th percentile of survival differences between scenarios was about zero, indicating that survival probabilities under the PA scenario were higher than under COS in 75 percent of years (fig. 16); however, the 75th percentile of survival differences was less than 0.03, indicating a small increase in survival probabilities in most years (fig. 16). Travel time (fig. 17) and routing to the Interior Delta (fig. 18) showed similar patterns, as did the survival rate for mid-April-June, but in the opposite direction.

Differences in survival (fig. 19), travel time (fig. 20), and routing (fig. 21) between scenarios varied among water year types and seasons. In the periods of October-December, survival differences were similar among water year types except during critically dry years, when there was less difference 
in survival between scenarios. In contrast, in April-June, and in wet years, differences in survival between scenarios were lower relative to below-normal, dry, and critical years (fig. 19). Similar patterns among water-year types were evident with respect to travel times (fig. 20) and routing to the Interior Delta (fig. 21).

Although our analysis with the STARS model provides insight about potential effects of the proposed action on juvenile salmon migrating through the Delta, several important limitations and assumptions could affect inferences drawn from the model. First, the sole drivers of survival, routing, and travel time in our model are DCC gate position and mean daily inflow to the Delta measured on the Sacramento River at Freeport. Thus, the results are insensitive to other factors that might influence survival and differ between scenarios, such as water exports from the Delta (Newman and Rice, 2002; Newman, 2003; Newman and Brandes, 2010). In addition, we note that in designing the scenarios of the Biological Assessment, USBR disaggregated the daily inflow into the Sacramento River from the monthly flows output by CALSIM II by using a constant value of the daily flow each month and smoothing the end-points of each month with a stiff spline. As a result, the STARS model results here display spurious jumps in the mean travel times and survival rates. Whereas these are smoothed somewhat by the averaging process for all the fish ensembles, care should be taken while interpreting the results of the model. This is not a model limitation; rather, it is a result of the adopted scenariodesign protocol.

Second, care should be taken when extending inferences beyond the range of data used to fit the model. Observed flows for the analysis conducted by Perry and others (2018) encompassed the 1st-95th percentiles of historical flow, bolstering inferences from the model about the effects of inflows; however, we note that the inflows, water export, and DCC gate operations in almost all of the PA and COS scenarios are within the range of data used to build the STARS model. Third, the model was fit to large hatchery-origin late-fall Chinook salmon smolts that migrated through the Delta during December-March, yet inferences were extended to all runs over the entire migration period (Perry and others, 2010; Michel and others, 2015). Thus, survival of other runs at other times of year could have a different response to operations under the proposed action. Last, because our model was fitted to juvenile- salmon telemetry data during 2005-2011, it is a representation of the Delta in its current state, not a future state. Because our model characterizes the relationship between Delta inflows and survival in the present-day Delta, it is insensitive to future changes to the Delta that modify the relation between inflows and survival. For example, Perry and others (2018) identified the strongest flowsurvival relations in reaches that transitioned from bidirectional tidal flows at low inflows to unidirectional river flow at high inflow, implicating tides as an important driver of the flow-survival relation. Future sea-level rise due to climate change will likely alter tidal dynamics in the Delta, and, in turn, could modify the relation between inflow and survival. Our model is insensitive to these types of changes to a future Delta.

Given these caveats, our analysis was able to (1) provide a comprehensive assessment of the proposed action by quantifying relative changes in key population metrics between scenarios, (2) estimate the magnitudes of these changes at given inflows and times of the year, and (3) shed light on the mechanisms driving differences between alternative management scenarios. Ultimately, these analyses and others completed for the Biological Opinion will be used to develop coordinated longterm operations of the SWP and CVP in a manner which minimizes the effects on listed species while facilitating water use that benefits the State of the California and the nation. 
$1979(\mathrm{WY}$ type $=\mathrm{BN})$
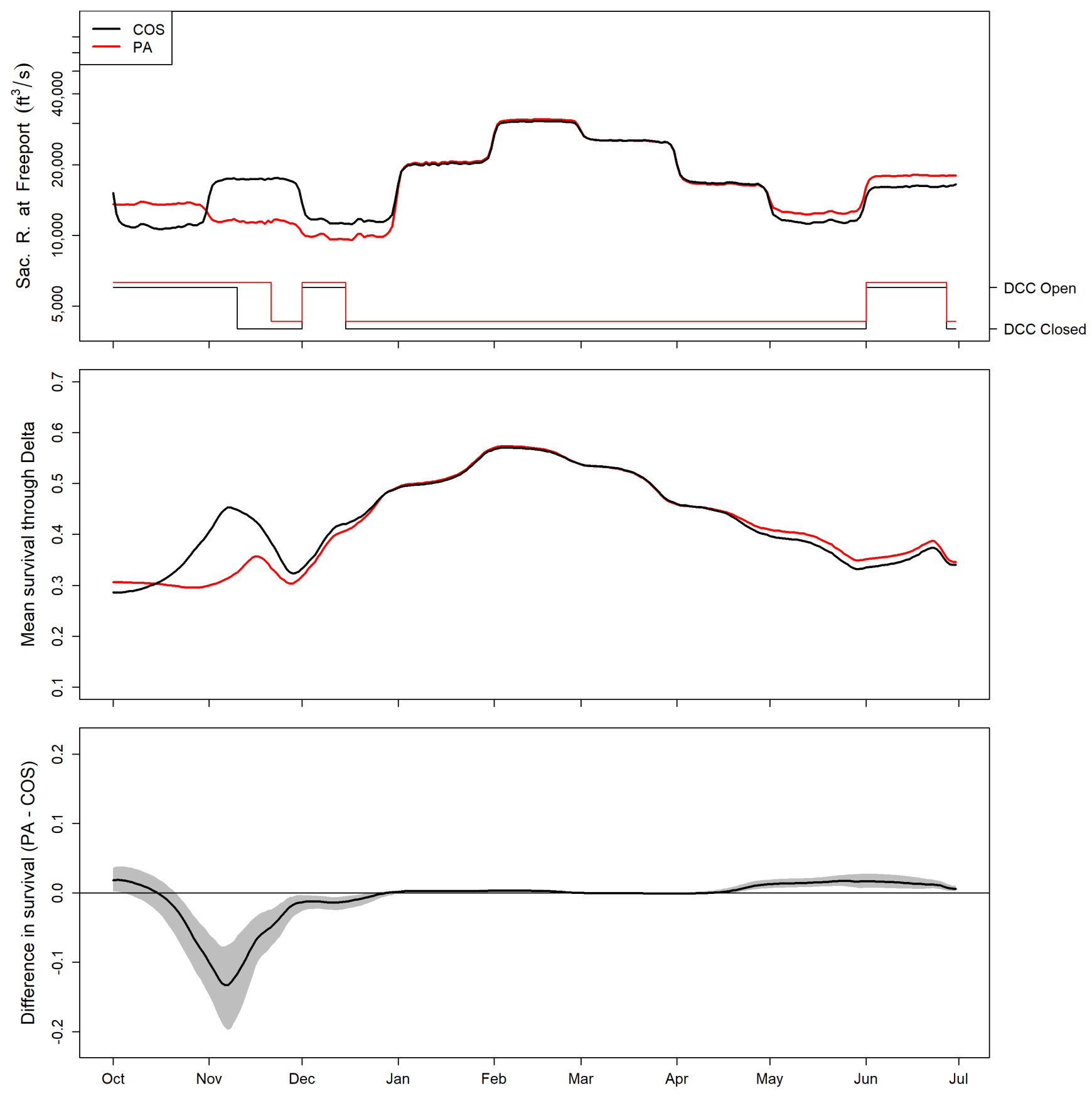

Figure 5. Graphs showing simulated daily river flow and Delta Cross Channel (DCC) gate operations for water year 1979 (top graph), medians of simulated mean daily survival probabilities through the SacramentoSan Joaquin River Delta, northern California (middle graph), and the difference in survival probabilities between the Proposed Action (PA) and Continuing Operation Scenario (COS) scenarios (bottom graph). Heavy lines in the top graph show discharge of the Sacramento River (Sac. R.) at Freeport on the primary yaxis, and thin lines show DCC operation (gate open or closed) on the second y-axis. Discharge in the top graph is shown on a logarithmic scale to highlight the variation in discharge when discharge is low. In the bottom graph, the gray-shaded region shows the 90-percent credible interval on the difference in survival between scenarios. BN, Below Normal; WY, water year; $\mathrm{ft} 3 / \mathrm{s}$, cubic foot per second. 

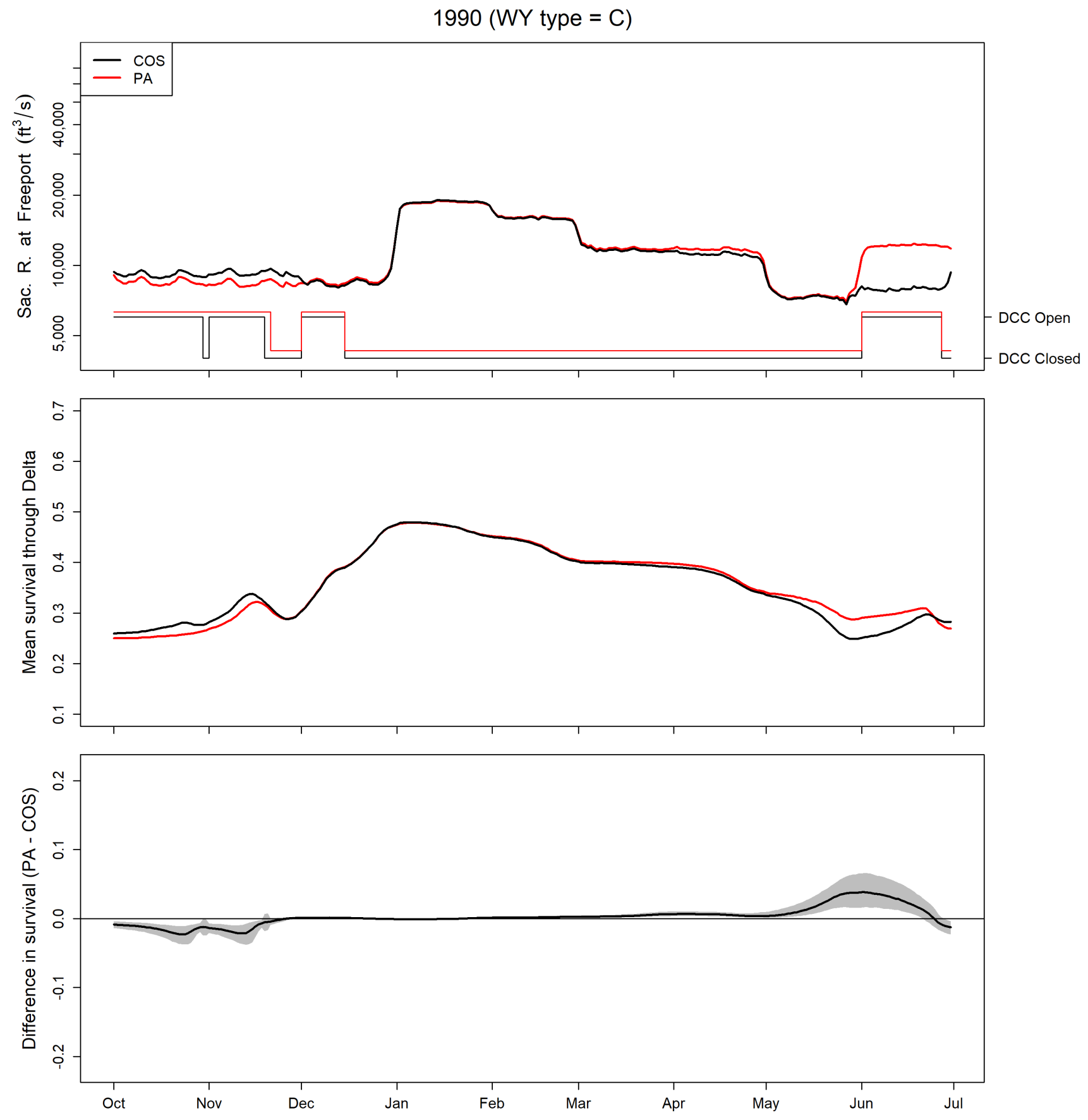

Figure 6. Graphs showing simulated daily river flow and Delta Cross Channel (DCC) gate operations for water year 1990 (top graph), median of simulated mean daily survival probabilities through the SacramentoSan Joaquin River Delta, northern California (middle graph), and the difference in survival probabilities between the Proposed Action (PA) and Continuing Operation Scenario (COS) scenarios (bottom graph). Heavy lines in the top graph shows discharge of the Sacramento River (Sac. R.) at Freeport on the primary yaxis, and thin lines show DCC operation (gate open or closed) on the second y-axis. Discharge in the top graph is shown on a logarithmic scale to highlight variation in discharge, especially when discharge is low. In the bottom graph, the gray-shaded region shows the 90-percent credible interval of the difference in survival rates between scenarios. C, Critical WY, water year; $\mathrm{ft}^{3} / \mathrm{s}$, cubic foot per second. 
$1979($ WY type $=$ BN $)$
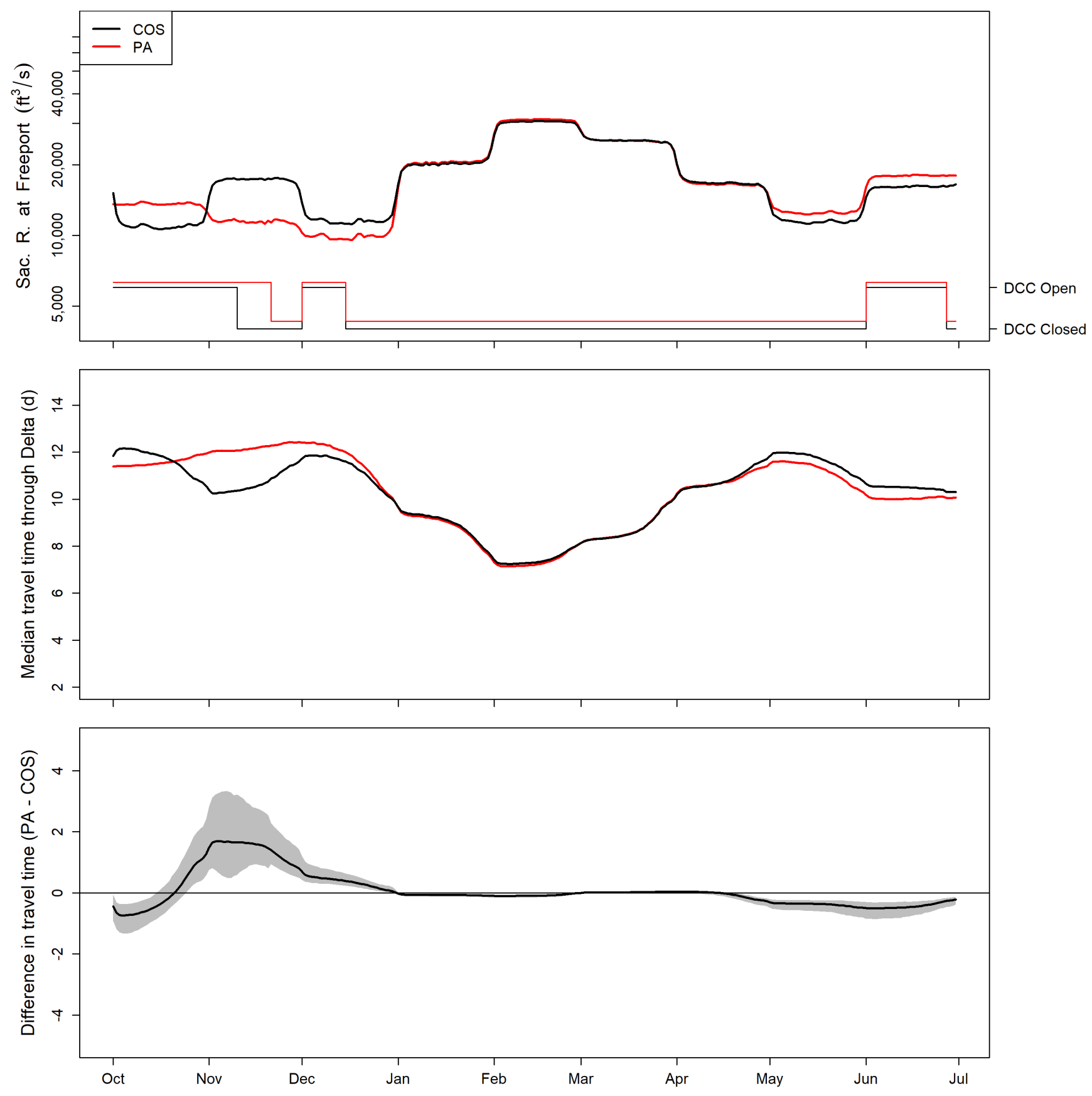

Figure 7. Graphs showing simulated daily river flow and Delta Cross Channel (DCC) gate operations for water year 1979 (top graph), simulated median daily travel time of juvenile Chinook salmon through the Sacramento-San Joaquin River Delta, northern California (middle graph), and the difference in travel times between the Proposed Action (PA) and Continuing Operation Scenario (COS) scenarios (bottom graph). Heavy lines in the top graph show discharge of the Sacramento River (Sac. R.) at Freeport on the primary yaxis, and thin lines show DCC operation (gate open or closed) on the second y-axis. Discharge in the top graph is shown on a logarithmic scale to highlight variation in discharge when discharge is low. In the bottom graph, the gray-shaded region shows the 90-percent credible interval of the difference in median travel times between scenarios. BN, Below Normal; WY, water year; $\mathrm{ft} 3 / \mathrm{s}$, cubic foot per second. 

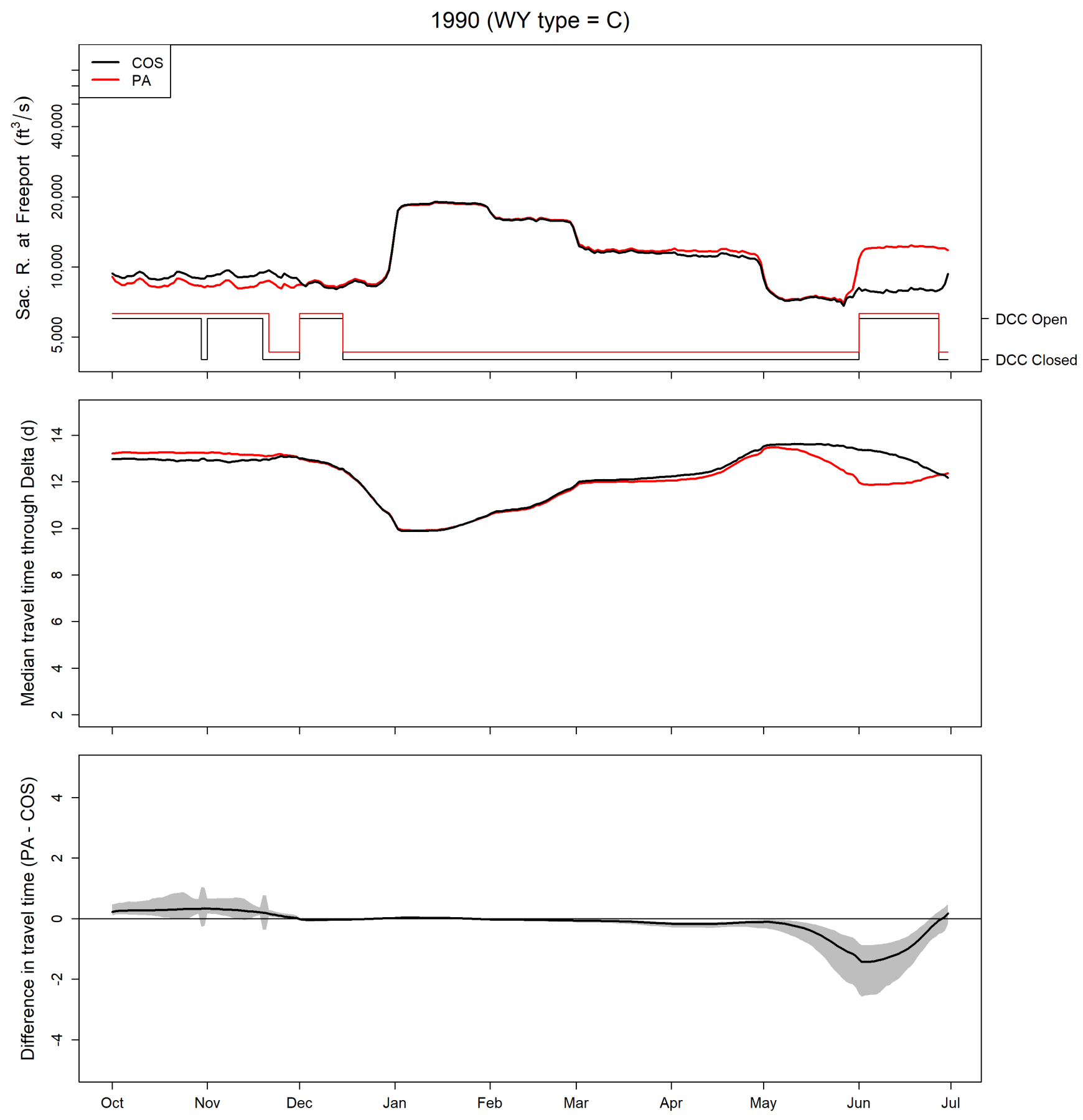

Figure 8. Graphs showing simulated daily river flow and Delta Cross Channel (DCC) gate operations for water year 1990 (top graph), simulated median daily travel time of juvenile Chinook salmon through the Sacramento-San Joaquin River Delta, northern California (middle graph), and the difference in travel time between the Proposed Action (PA) and Continuing Operation Scenario (COS) scenarios (bottom graph). Heavy lines in the top graph show discharge of the Sacramento River (Sac. R.) at Freeport on the primary yaxis, and thin lines show DCC operation (gate open or closed) on the second y-axis. Discharge in the top graph is shown on a logarithmic scale to highlight variation in discharge when discharge is low. In the bottom graph, the gray-shaded region shows the 90-percent credible interval of the difference in median travel time between scenarios. C, Critical WY, water year; $\mathrm{ft}^{3} / \mathrm{s}$, cubic foot per second. 
$1979($ WY type = BN $)$
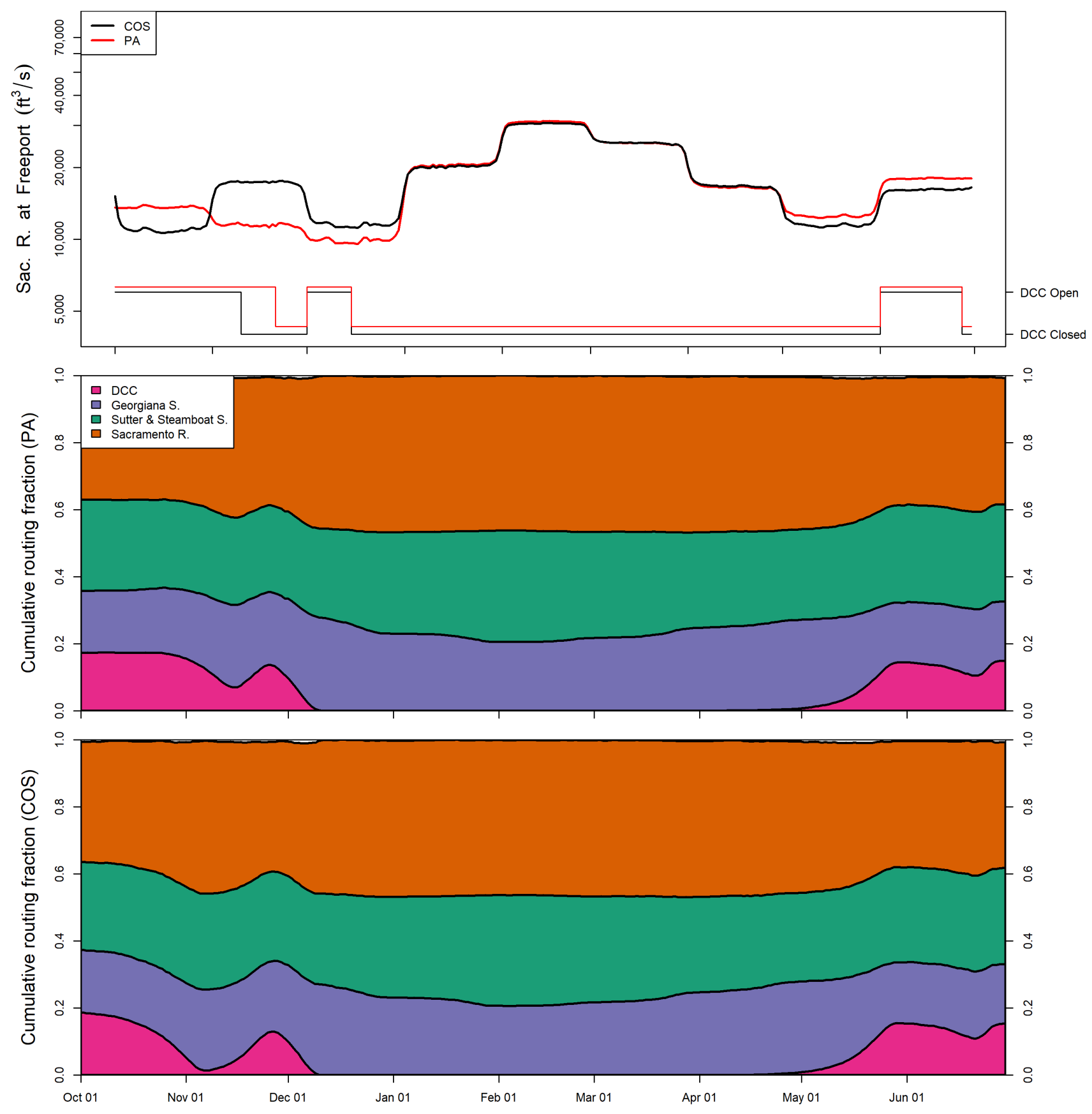

Figure 9. Graphs showing simulated daily river flow and Delta Cross Channel (DCC) gate operations for water year 1979 (top graph), and stacked line plots showing the daily cumulative migration-route probabilities for the Proposed Action (PA, middle graph) and Continuing Operation Scenario (COS, bottom graph) scenarios, Sacramento-San Joaquin River Delta, northern California. Heavy lines in the top graph show discharge of the Sacramento River (Sac. R.) at Freeport on the primary y-axis, and thin lines show DCC operation (gate open or closed) on the second y-axis. Discharge in the top graph is shown on a logarithmic scale to highlight variation in low discharge values. BN, Below Normal; WY, water year; $\mathrm{ft} / 3 / \mathrm{s}$, cubic foot per second. 
$1990($ WY type $=$ C)
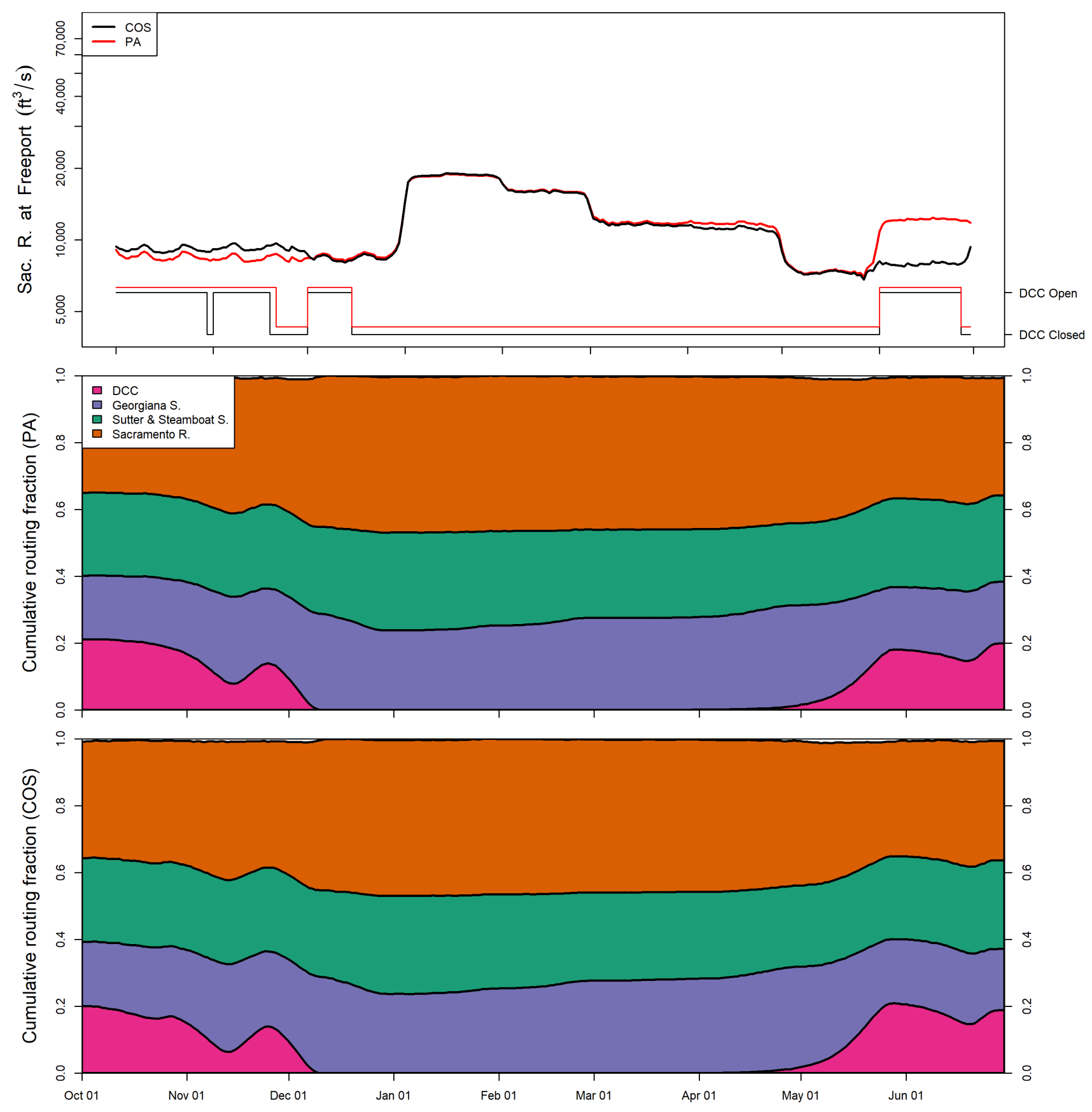

Figure 10. Graphs showing simulated daily river flow and Delta Cross Channel (DCC) gate operations for water year 1990 (top graph), and stacked line plots showing the daily cumulative migration-route probabilities for the Proposed Action (PA, middle graph) and Continuing Operation Scenario (COS, bottom graph) scenarios, Sacramento-San Joaquin River Delta, northern California. Heavy lines in the top graph show discharge of the Sacramento River (Sac. R.) at Freeport on the primary y-axis, and thin lines show DCC operation (gate open or closed) on the second y-axis. Discharge in the top graph is shown on a logarithmic scale to highlight variation in low discharge values. C, Critical; WY, water year; $\mathrm{ft} 3 / \mathrm{s}$, cubic foot per second. 
$1979($ WY type $=$ BN $)$
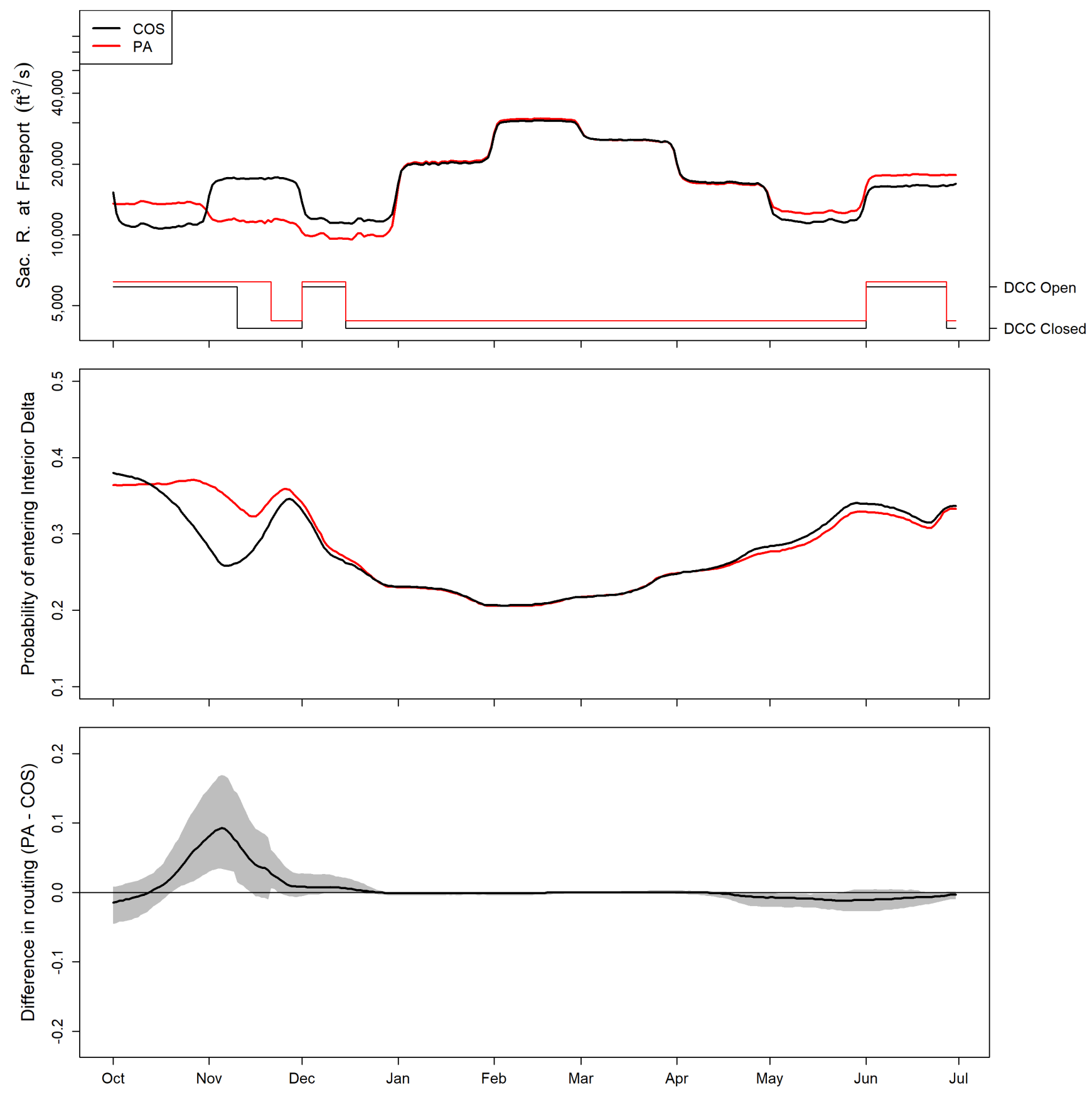

Figure 11. Graphs showing simulated daily river flow and Delta Cross Channel (DCC) gate operations for water year 1979 (top graph), simulated median probability of entering the Interior Delta through the Delta Cross Channel or Georgiana Slough (middle graph), and the difference in routing between the Proposed Action (PA) and Continuing Operation Scenario (COS) scenarios (bottom graph). Heavy lines in the top graph show discharge of the Sacramento River (Sac. R.) at Freeport on the primary y-axis, and thin lines show DCC operation (gate open or closed) on the second y-axis. Discharge in the top graph is shown on a logarithmic scale to highlight variation in low discharge values. In the bottom graph, the gray-shaded region shows the 90 -percent credible interval of the difference in routing between scenarios. BN, Below Normal; WY, water year; $\mathrm{ft}^{3} / \mathrm{s}$, cubic foot per second. 

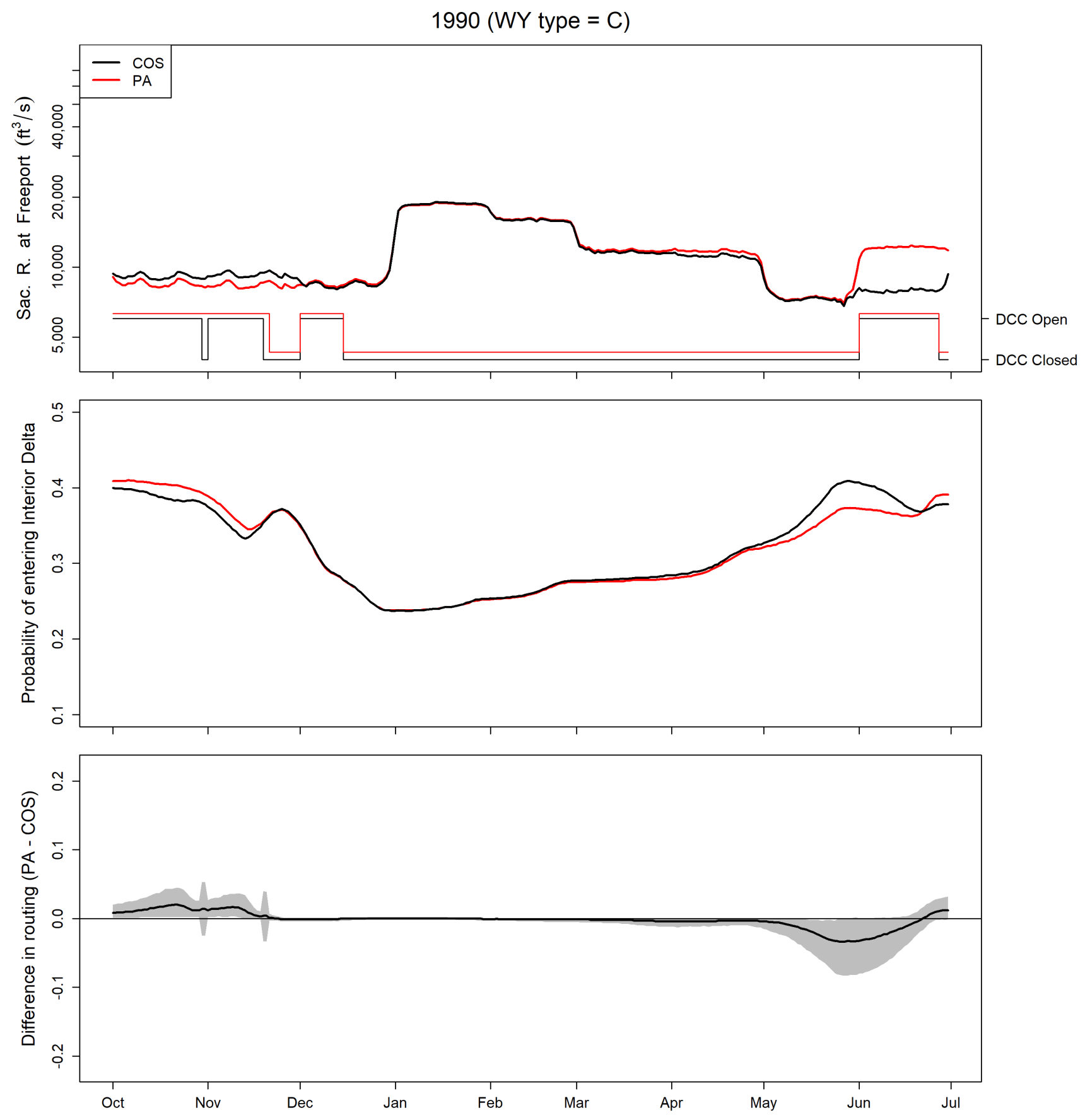

Figure 12. Graphs showing simulated daily river flow and Delta Cross Channel (DCC) gate operations for water year 1990 (top graph), simulated median probability of entering the Interior Delta through the Delta Cross Channel or Georgiana Slough (middle graph), and the difference in routing between the Proposed Action (PA) and Continuing Operation Scenario (COS) scenarios (bottom graph). Heavy lines in the top graph show discharge of the Sacramento River (Sac. R.) at Freeport on the primary y-axis, and thin lines show DCC operation (gate open or closed) on the second $y$-axis. Discharge in the top graph is shown on a logarithmic scale to highlight variation in low discharge values. In the bottom graph, the gray-shaded region shows the 90-percent credible interval of the difference in routing between scenarios. C, Critical; WY, water year; $\mathrm{ft}^{3} / \mathrm{s}$, cubic foot per second. 


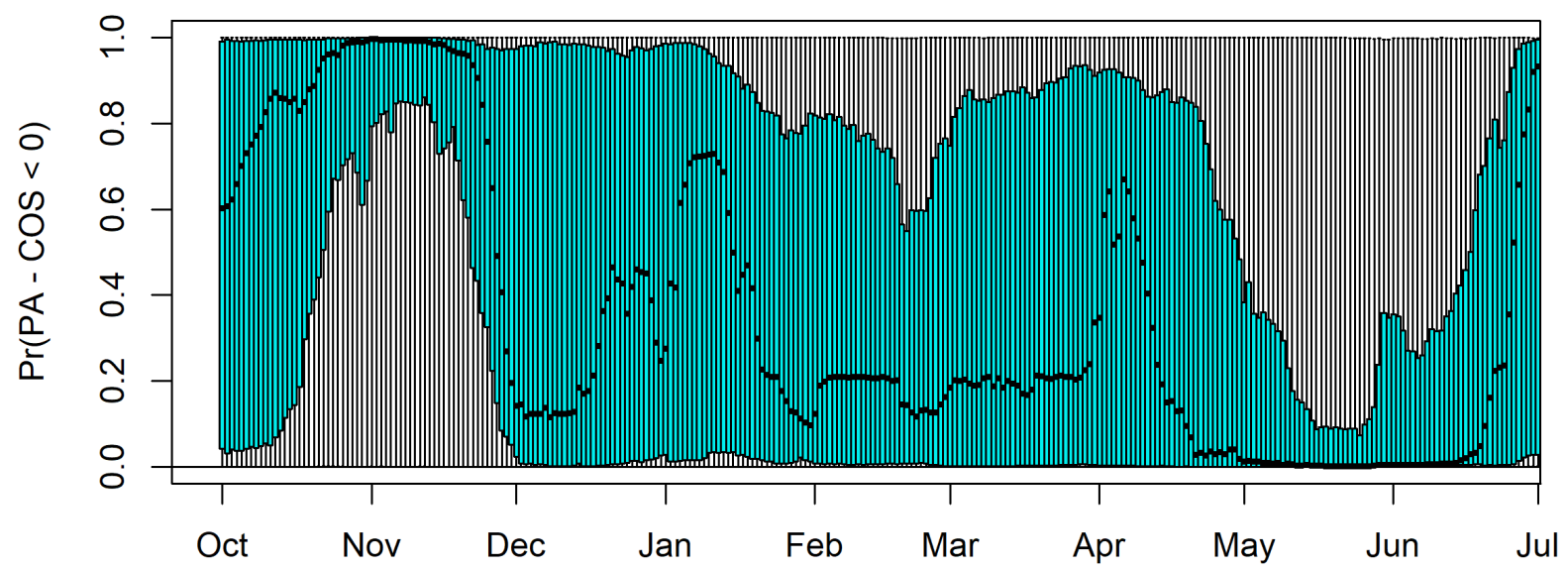

Figure 13. Boxplots showing the distribution of the probability that through-Delta survival under the Proposed Action (PA) scenario is less than the probability of survival under the Continuing Operation Scenario (COS). Each boxplot represents the distribution among the 82 years for a given date of the probability that the difference between PA and COS is less than zero. The point in each box represents the median, the box hinges bounding the shaded blue area represent the 25th and 75 th percentiles, and the whiskers display the minimum and maximum. Pr, probability; <, less than.

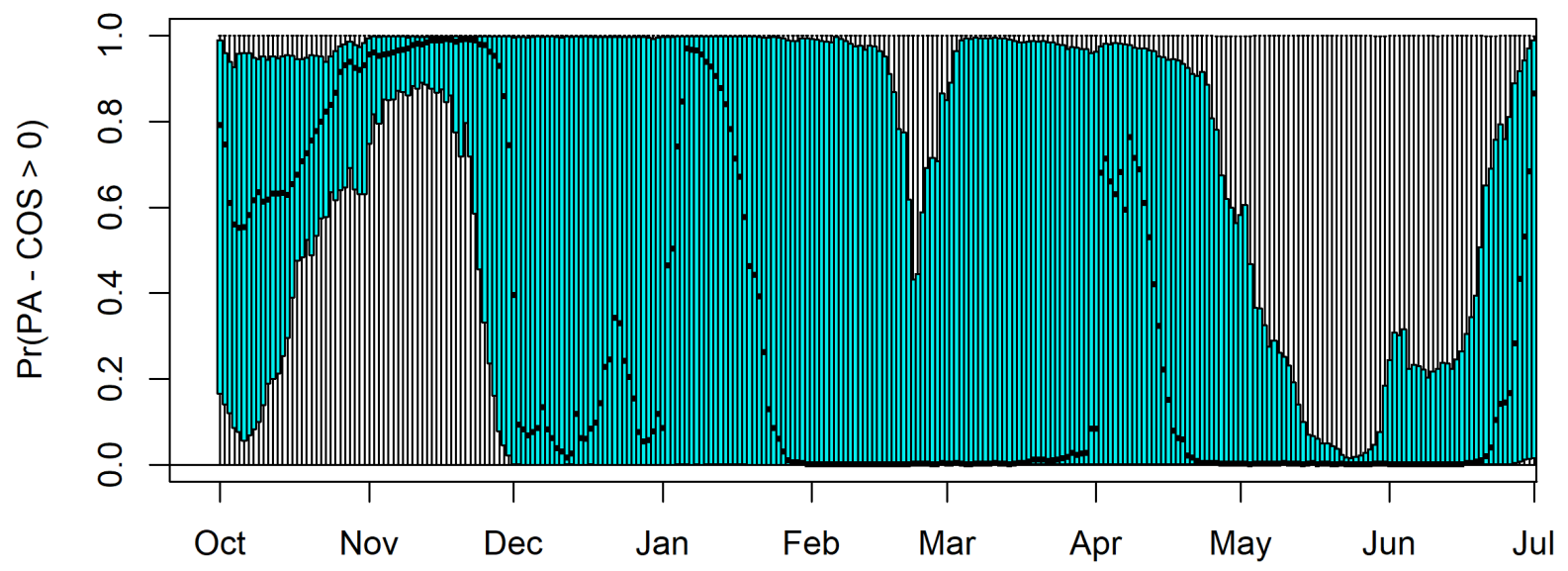

Figure 14. Boxplots showing the distribution of the probability that the difference in median travel time through the Delta between the Continuing Operation Scenario (COS) and the Proposed Action (PA) scenario is greater than zero. Each boxplot represents the distribution among the 82 years for a given date of the probability that the difference between PA and COS is greater than zero. The point in each box represents the median, the box hinges bounding the shaded blue area represent the 25th and 75th percentiles, and the whiskers display the minimum and maximum. Pr, probability; >, greater than. 


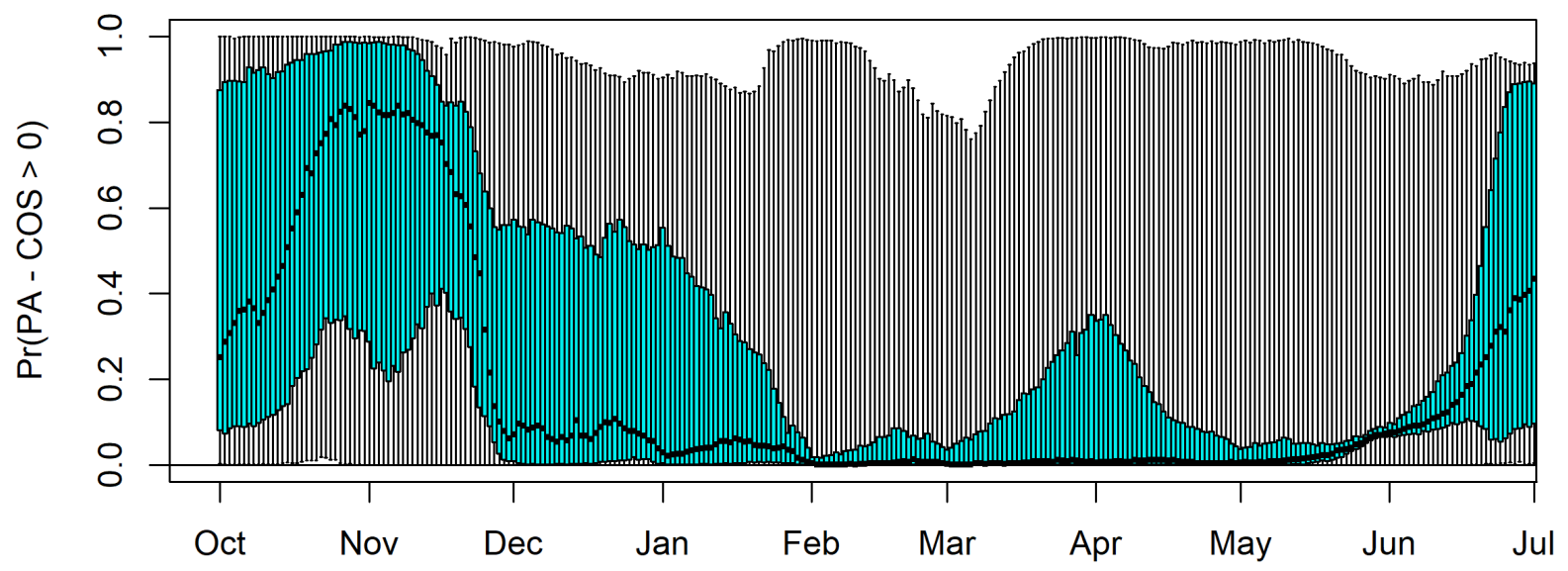

Figure 15. Boxplots showing the distribution of the probability that the difference in being routed into the Interior Delta between the Continuing Operation Scenario (COS) and Proposed Action (PA) scenario is greater than zero. Each boxplot represents the distribution among the 82 years for a given date of the probability that the difference between PA and COS is greater than zero. The point in each box represents the median, the box hinges bounding the shaded blue area represent the 25th and 75th percentiles, and the whiskers display the minimum and maximum. Pr, probability; >, greater than.

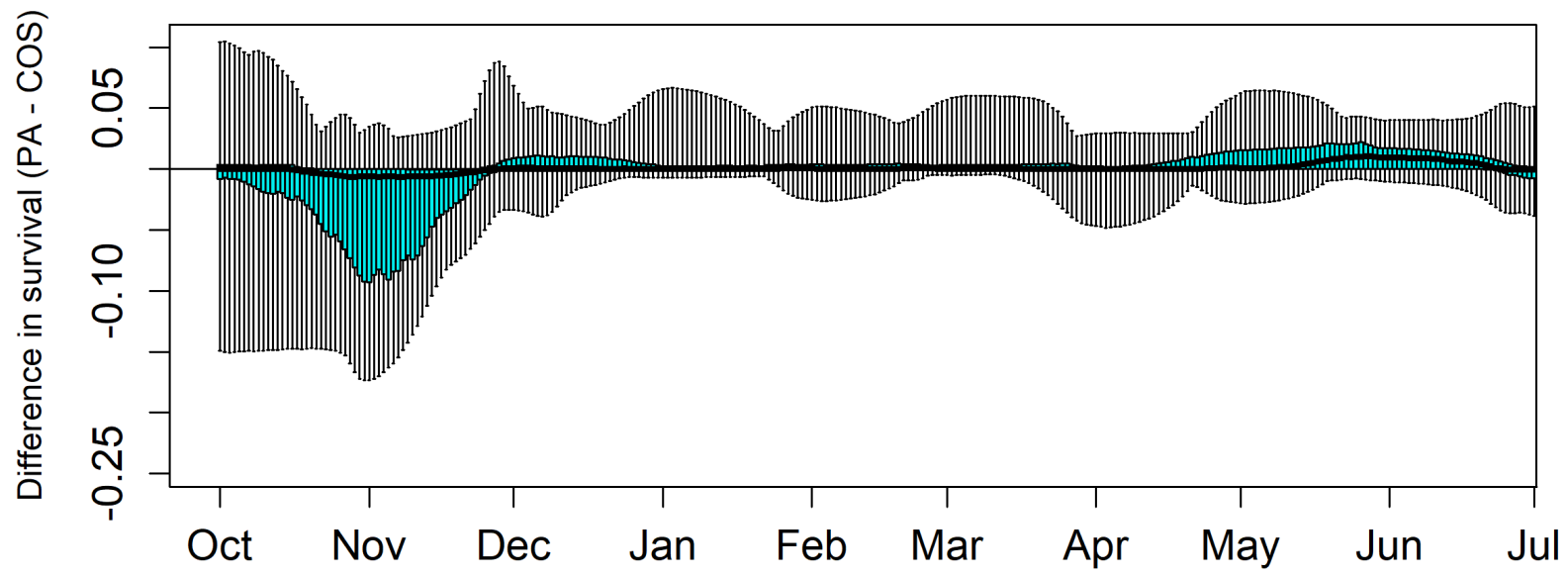

Figure 16. Boxplots of daily median differences in through-Delta survival between the Proposed Action (PA) scenario and Continuing Operation Scenario (COS). Each boxplot represents the distribution of median survival differences among the 82 years for a given date. The point in each box represents the median, the box hinges bounding the shaded blue area represent the 25 th and 75 th percentiles, and the whiskers display the minimum and maximum. 


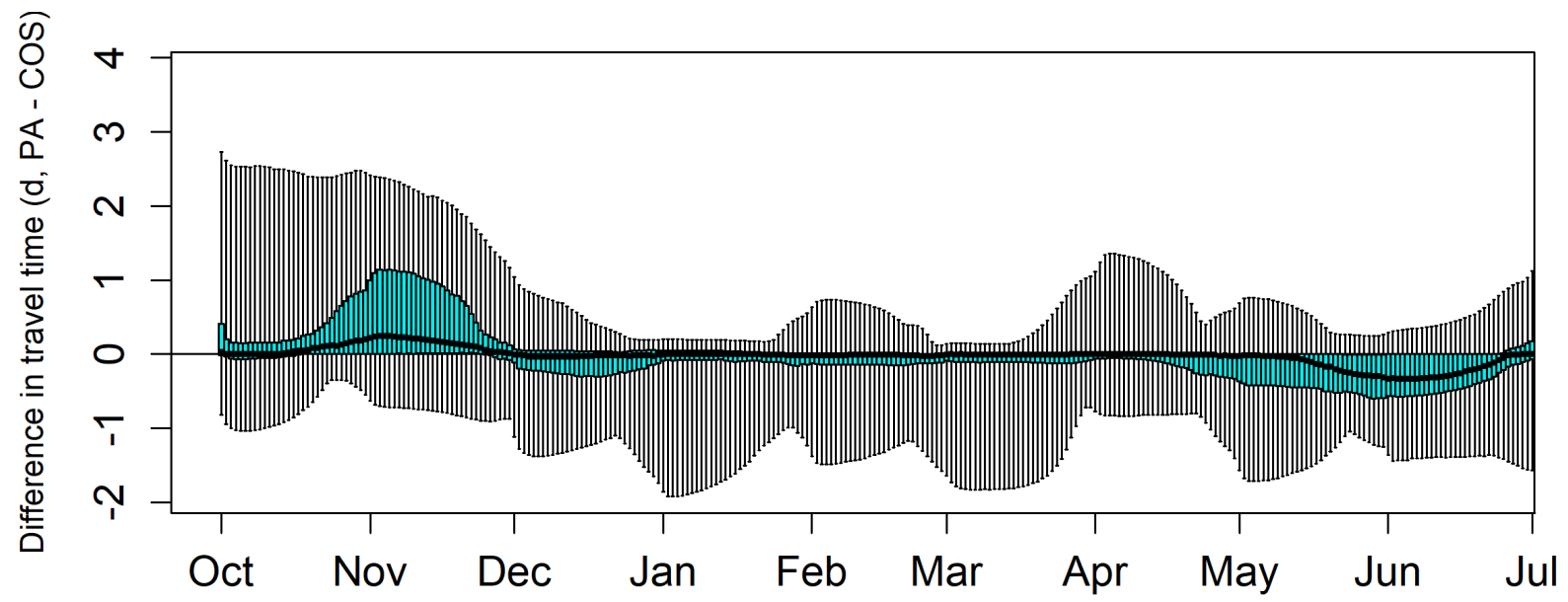

Figure 17. Daily boxplots of differences in median travel time between the Proposed Action (PA) scenario and Continuing Operation Scenario (COS). Each boxplot represents the distribution of median travel-time differences among the 82 years for a given date. The point in each box represents the median, the box hinges bounding the shaded blue area represent the 25 th and 75 th percentiles, and the whiskers display the minimum and maximum. $d$, days.

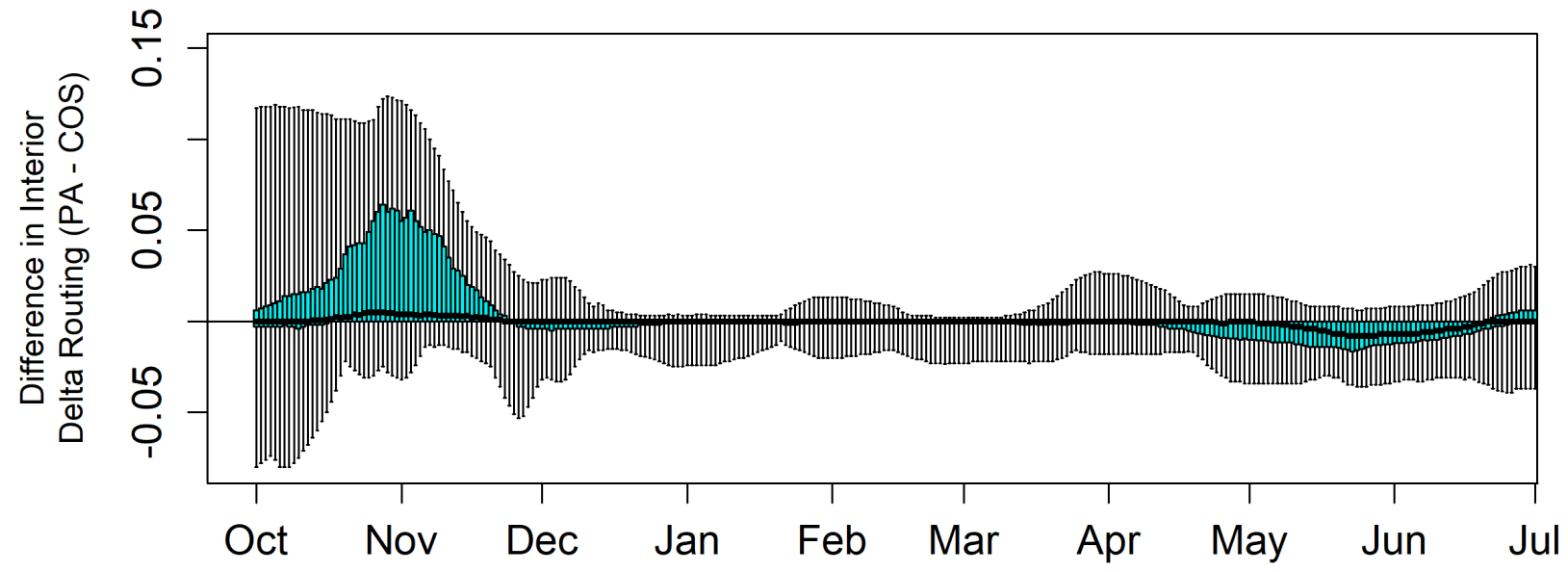

Figure 18. Daily boxplots of differences in routing to the Interior Delta between the Proposed Action (PA) scenario and Continuing Operation Scenario (COS). Each boxplot represents the distribution of median routing differences among the 82 years for a given date. The point in each box represents the median, the box hinges bounding the shaded blue area represent the 25 th and 75 th percentiles, and the whiskers display the minimum and maximum. 

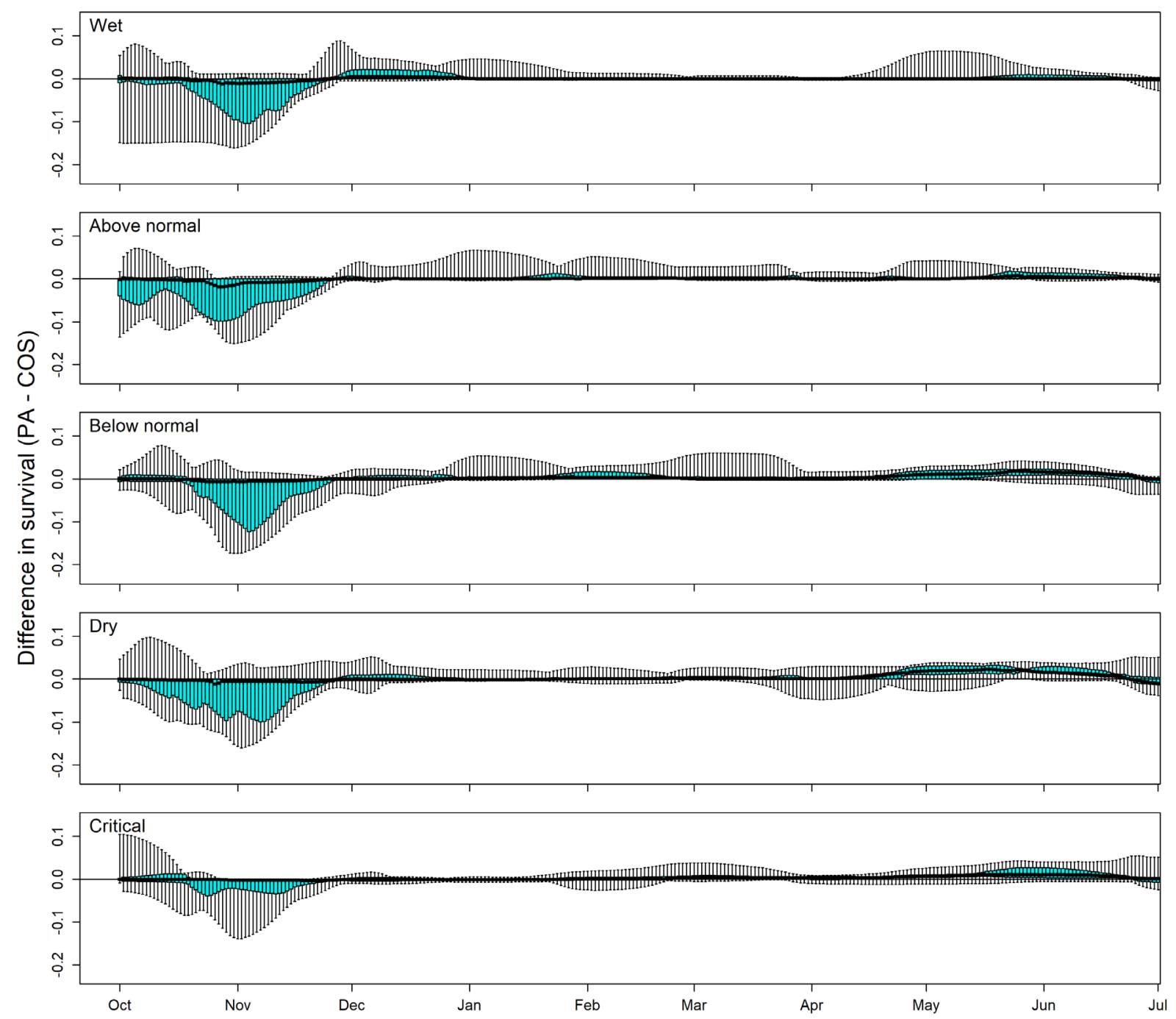

Figure 19. Daily boxplots of median differences in through-Delta survival rates between the Proposed Action (PA) scenario and Continuing Operation Scenario (COS) by water-year type. Each boxplot represents the distribution of median survival-rate differences among the 82 years for a given date. The point in each box represents the median, the box hinges bounding the shaded blue area represent the 25th and 75th percentiles, and the whiskers display the minimum and maximum. 

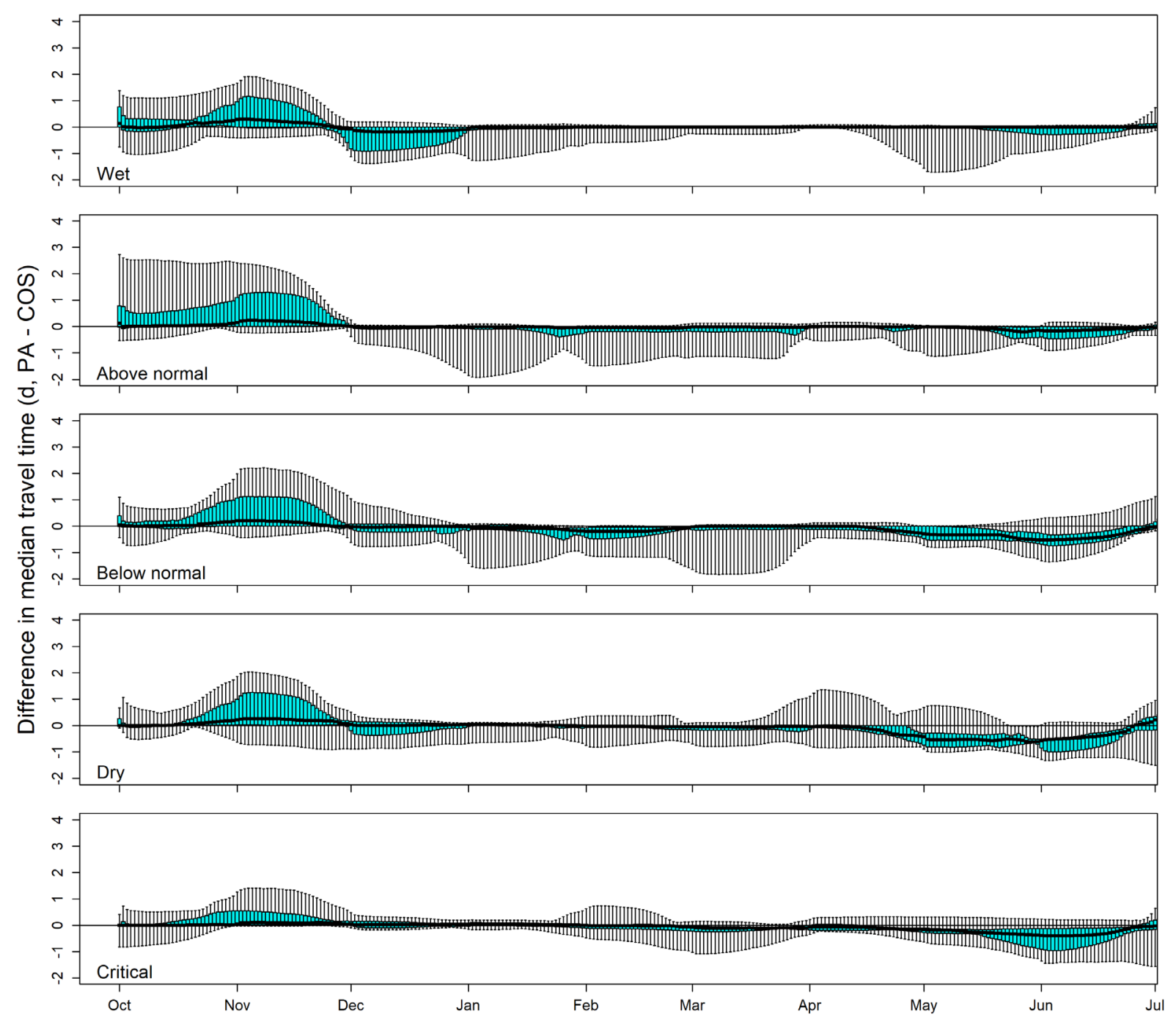

Figure 20. Daily boxplots of median differences in median travel times between the Proposed Action (PA) scenario and Continuing Operation Scenario (COS) by water-year type. Each boxplot represents the distribution of median travel-time differences among the 82 years for a given date. The point in each box represents the median, the box hinges bounding the shaded blue area represent the 25th and 75th percentiles, and the whiskers display the minimum and maximum. $d$, days. 

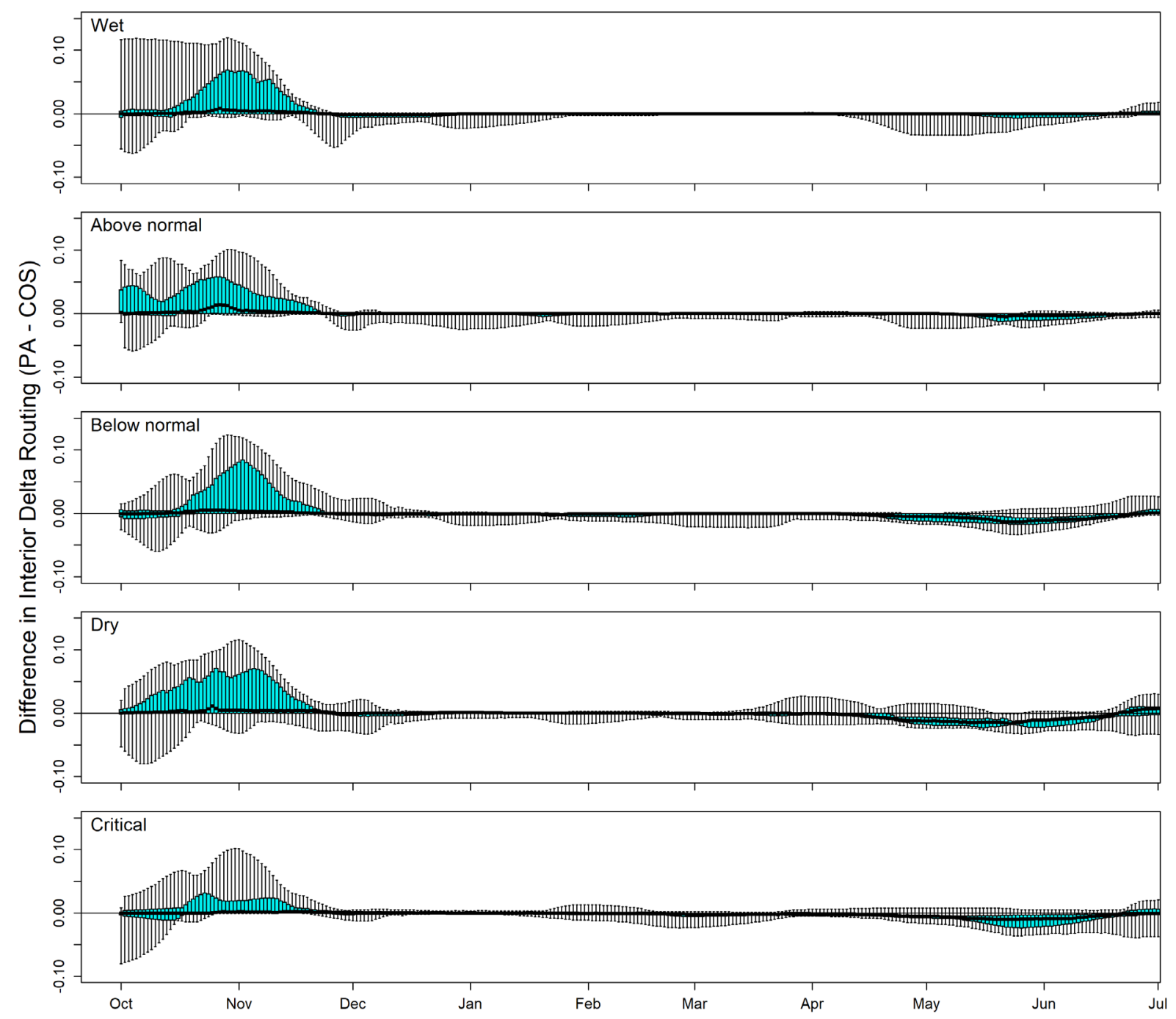

Figure 21. Daily boxplots of median differences in routing to the Interior Delta between the Proposed Action (PA) scenario and Continuing Operation Scenario (COS) by water-year type. Each boxplot represents the distribution of median travel-time differences among years for a given date. The point in each box represents the median, the box hinges bounding the shaded blue area represent the 25th and 75th percentiles, and the whiskers display the minimum and maximum. $d$, days. 


\section{References Cited}

ICF International, 2016, Biological assessment for the California WaterFix: Prepared for the Bureau of Reclamation, Sacramento, California, ICF 00237.15., 62 p.

Kapahi, G., Baer, I., Farwell, J., Riddle, D., and Wilson, G., 2006, Water quality control plan for the San Francisco Bay/Sacramento-San Joaquin Delta Estuary: Sacramento, California, State Water Resources Control Board, 49 p.

King, R., Morgan, B., Gimenez, O., and Brooks, S., 2010, Bayesian analysis for population ecology: Boca Raton, Florida, CRC Press, 456 p.

Michel, C.J., Ammann, A.J., Lindley, S.T., Sandstrom, P.T., Chapman, E.D., Thomas, M.J., Singer, G.P., Klimley, A.P., and MacFarlane, R.B., 2015, Chinook salmon outmigration survival in wet and dry years in California's Sacramento River: Canadian Journal of Fisheries and Aquatic Sciences, v. 72, no. 11, p. 1749-1759, https://doi.org/10.1139/cjfas-2014-0528.

National Marine Fisheries Service (NMFS), 2009, Biological opinion and conference opinion on the longterm operations of the Central Valley Project and State Water Project: National Marine Fisheries Service, Southwest Region, 844 p. accessed May 29, 2019, at https://www.westcoast.fisheries.noaa.gov/central_valley/water_operations/ocap.html.

Newman, K.B., 2003, Modelling paired release-recovery data in the presence of survival and capture heterogeneity with application to marked juvenile salmon: Statistical Modelling, v. 3, no. 3, p. 157177, https://doi.org/10.1191/1471082X03st055oa.

Newman, K.B., and Rice, J., 2002, Modeling the survival of Chinook salmon smolts outmigrating through the lower Sacramento River system: Journal of the American Statistical Association, v. 97, no. 460, p. 983-993, https://doi.org/10.1198/016214502388618771.

Newman K.B., and Brandes P.L. 2010. Hierarchical modeling of juvenile Chinook salmon survival as a function of Sacramento-San Joaquin Delta water exports: North American Journal of Fisheries Management, v. 30, p. 157-169, http://dx.doi.org/10.1577/M07-188.1.

Perry, R.W., 2010, Survival and migration dynamics of juvenile Chinook salmon (Oncorhynchus tshawytscha) in the Sacramento-San Joaquin River Delta: Seattle, University of Washington, School of Aquatic and Fishery Sciences, Ph.D. dissertation, 223 p.

Perry, R.W., Skalski, J.R., Brandes, P.L., Sandstrom, P.T., Klimley, A.P., Ammann, A., and MacFarlane, B., 2010, Estimating survival and migration route probabilities of juvenile Chinook salmon in the Sacramento-San Joaquin River Delta: North American Journal of Fisheries Management, v. 30, no. 1, p. 142-156, https://doi.org/10.1577/M08-200.1.

Perry, R.W., Brandes, P.L., Burau, J.R., Klimley, A.P., MacFarlane, B., Michel, C., and Skalski, J.R., 2013, Sensitivity of survival to migration routes used by juvenile Chinook salmon to negotiate the Sacramento-San Joaquin River Delta: Environmental Biology of Fishes, v. 96, nos. 2-3, p. 381-392, https://doi.org/10.1007/s10641-012-9984-6.

Perry, R.W., Romine, J.G., Adams, N.S., Blake, A.R., Burau, J.R., Johnston, S.V., and Liedtke, T.L., 2014, Using a non-physical behavioral barrier to alter migration routing of juvenile Chinook salmon in the Sacramento-San Joaquin River Delta: River Research and Applications, v. 30, no. 2, p. 192203, https://doi.org/10.1002/rra.2628.

Perry, R.W., Brandes, P.L., Burau, J.R., Sandstrom, P.T., and Skalski, J.R., 2015, Effect of tides, river flow, and gate operations on entrainment of juvenile salmon into the interior Sacramento-San Joaquin River Delta: Transactions of the American Fisheries Society, v. 144, no. 3, p. 445-455, https://doi.org/10.1080/00028487.2014.1001038.

Perry, R.W., Pope, A.C., Romine, J.G., Brandes, P.L., Burau, J.R., Blake, A.R., Ammann, A.J., and Michel, C.J., 2018, Flow-mediated effects on travel time, routing, and survival of juvenile Chinook salmon in a spatially complex, tidally forced river delta: Canadian Journal of Fisheries and Aquatic Sciences, v. 75, no. 11, p. 1886-1901, https://doi.org/10.1139/cjfas-2017-0310. 
U.S. Bureau of Reclamation, 2019, Reinitiation of consultation on the coordinated long-term operation of the Central Valley Project and State Water Project: Final Biological Assessment, 871 p., accessed May 29, 2019, at https://www.usbr.gov/mp/bdo/lto.html.

Zabel, R. W., 2002., Using "travel time" data to characterize the behavior of migrating animals: The American Naturalist, v. 159, no. 4, p. 372-387, https://www.jstor.org/stable/10.1086/338993. 


\section{Appendixes}

Appendixes 1-4 are Adobe Acrobat ${ }^{\circledR}$ files and are available for download at https://doi.org/10.3133/ofr20191125.

Appendix 1. Simulated Daily Survival by Year, Continuing Operations Compared to Proposed Action Scenarios, 1922-2003

Appendix 2. Simulated Daily Travel Time by Year, Continuing Operations Compared to Proposed Action Scenarios, 1922-2003

Appendix 3. Simulated Daily Routing by Year, Continuing Operations Compared to Proposed Action Scenarios, 1922-2003

Appendix 4. Simulated Proportion of Fish Entering the Interior Delta by Year Continuing Operations Compared to Proposed Action Scenarios, 1922-2003 
Publishing support provided by the U.S. Geological Survey Science Publishing Network, Tacoma Publishing Service Center

For more information concerning the research in this report, contact the Director, Western Fisheries Research Center

U.S. Geological Survey

6505 NE 65th Street

Seattle, Washington 98115-5016

https://www.usgs.gov/centers/wfrc 
훙.

옹

ఠ

홍

흠

을

ำ

تำ

今

ڤ

흘

苞

응.

T)

음 